\title{
COMPATIBILIDAD ENTRE EL DERECHO A LA LIBRE CONTRATACIÓN Y LA FIJACIÓN DE SALARIOS POR LEY (A PROPÓSITO DE LA LEY No 20.281 SOBRE SUELDO BASE)
}

\author{
COMPATIBILITY BETWEEN THE RIGHT TO FREEDOM OF \\ CONTRACT WITH THE LEGISLATIVE POWER TO ESTABLISH \\ SALARIES (BECAUSE OF No 20.281 ACT ON BASE SALARY)
}

\author{
ARTURO FERMANDOIS VÖHRINGER* \\ José FranCISCO GaRCÍA GARCÍA ${ }^{* *}$
}

\begin{abstract}
RESUMEN: Sobre la base del análisis de la ley No 20.281, que modifica el Código del Trabajo en materia de salarios base, los autores revisan críticamente la forma en que, en este caso, la Presidencia hizo uso de su iniciativa legislativa exclusiva en materia de aumento de remuneraciones del sector privado, infringiendo el derecho a la libre contratación garantizado en la Carta Fundamental. En este sentido, en el artículo se propone, utilizando una interpretación constitucional sistemática, la necesidad de armonizar dicha facultad presidencial con la garantía relativa a la libertad de trabajo consagrada en el artículo 19 No 16 de la Constitución Política, la que no puede ser considerada una garantía aislada, sino componente esencial de la Constitución Económica consagrada en la Constitución de 1980.
\end{abstract}

Palabras clave: libertad de trabajo, derecho a la libre de contratación, derecho laboral, orden público económico, constitución económica, regulación económica, iniciativa legislativa exclusiva presidencial.

ABSTRACT: Through the analysis of the 20.281 Act, that modifies base salaries established the Labor Code, the authors criticize the way that, in this case, the Presidency used its exclusive legislative initiative for increasing private sector' salaries, infringing the right to freedom of contract established by the Constitution. In this sense, the paper propose, using a systematic constitutional interpretation method, reconciling this power with the right of freedom to work stipulated in article 19 No 16 of the Constitution, right that can not be considered as an isolated guarantee, but an essential component of the Economic Constitution established in the Constitution of 1980.

Key words: freedom to work, right to freedom of contract, Labor Law, economic public order, economic constitution, economic regulation, executive exclusive legislative initiative.

* Licenciado en Ciencias Jurídicas, Pontificia Universidad Católica de Chile, Máster en Políticas Públicas, Universidad de Harvard. Profesor de Derecho Constitucional, Pontificia Universidad Católica de Chile. Correo electrónico: afermandois@fermandois.cl

** Licenciado en Ciencias Jurídicas, Pontificia Universidad Católica de Chile. Máster (LL.M) y Doctor en Derecho (JSD), Universidad de Chicago. Profesor de Derecho Constitucional, Universidad del Desarrollo.

Correo electrónico: jfgarcia@moralesybesa.cl 


\section{INTRODUCCIÓN}

La ley No 20.281, de agosto de 2008, trajo a nuestro debate constitucional un asunto inédito: ¿puede la ley aumentar los sueldos del sector privado más allá del ingreso mínimo? ¿Puede hacerlo el legislador cuando le parezca conveniente, al margen, o aun contra la voluntad de trabajadores y empleadores, así expresada en sus contratos individuales o luego de una negociación colectiva? Esta ley, originalmente conocida como de modificación de salarios base y luego como ley de semana corrida ${ }^{1}$ puso a prueba categorías propias del derecho constitucional laboral escasamente profundizadas. Obligó, ahora desde la óptica del ius publicismo, a revisar la forma como nuestra dogmática entiende, y ha entendido históricamente, el alcance real que tiene la libertad de trabajo en la Carta Fundamental.

Lo anterior se detonó porque ley No 20.281 impuso un aumento significativo de remuneraciones a los trabajadores del sector privado, por la vía de extender el derecho al pago del día de descanso semanal a trabajadores contratados por mes ${ }^{2}$. Con ello levantó la pregunta respecto de si dicho aumento equivale, ante la Constitución, a permitir que el legislador pueda alterar un elemento esencial del contrato de trabajo, que es precisamente la remuneración del mismo, reemplazando la voluntad del empleador y del trabajador que le dieron nacimiento.

$\mathrm{Y}$ es que en esta materia resulta clave considerar, por un lado, que es la propia Constitución la que parece amparar esta atribución del legislador, al incluir en el artículo 65 número 4, dentro de las materias de iniciativa exclusiva del Presidente de la República, aquellas consistentes en "fijar las remuneraciones minimas del sector privado, aumentar obligatoriamente sus remuneraciones y demás beneficios económicos o alterar las bases que sirvan para determinarlos (...)". Este precepto proviene de la Carta de 1925.

Pero por otro, y en aparente dicotomía, la Carta Fundamental asegura a todas las personas (y especialmente a trabajadores y empleadores) "el derecho a la libre contratación y a la libre elección del trabajo con una justa retribución (...)"3; lo que naturalmente envuelve el derecho a pactar al menos ciertas bases nucleares, mínimas y esenciales del contrato de trabajo. Además, la misma Carta Fundamental concede a los trabajadores el derecho a "la negociación colectiva con la empresa en que laboren", y remite a la ley el establecimiento de "los procedimientos adecuados para lograr en ella una solución justa y pacifica" ", lo que debe entenderse en relación al pacto de los elementos esenciales de los contratos (colectivos) de trabajo.

\footnotetext{
${ }^{1}$ Promulgada el día 3 de agosto y publicada en el Diario Oficial el día 21 de agosto, ambos de 2008.

2 Este aumento de remuneraciones se ordena específicamente en el Artículo Único, No 3 de la ley, que modifica el artículo 45 del Código del Trabajo de la siguiente forma: "Agrégase, en el inciso primero del artículo 45, a continuación del punto aparte (.), que pasa a ser punto seguido (.), la siguiente oración:"Igual derecho tendrá el trabajador remunerado por sueldo mensual y remuneraciones variables, tales como comisiones o tratos, pero, en este caso, el promedio se calculará solo en relación a la parte variable de sus remuneraciones".

${ }^{3}$ Artículo $19 \mathrm{~N}^{\circ} 16$, inciso segundo Constitución Política de la República (CPR).

${ }^{4}$ Artículo $19 \mathrm{~N}^{\circ} 16$, inciso $5^{\circ} \mathrm{CPR}$.
} 
Y si bien la garantía contemplada en el numeral 16 del artículo 19 de la Constitución Política ha sido normalmente estudiada en cuanto a los trabajos lícitos y los trabajos prohibidos, esto es, en cuanto a la libre elección de un trabajo u oficio ${ }^{5}$, poco se ha reflexionado sobre el contenido de la segunda parte, aquella que apunta a la autonomía contractual, esto es, a la facultad de trabajador y empleador de contratar.

Este trabajo planteará la tesis consistente en que si bien la Constitución confiere un margen razonable al legislador para definir los parámetros bajo los cuales un contrato de trabajo debe ser celebrado, esta facultad limita con la esencia de la libre contratación, asegurada en el mismo Código Máximo.

Así, si bien en virtud del principio general de la regulación y complementación por ley de los derechos constitucionales derivada del artículo 19 numeral 26 de la Constitución la doctrina ha admitido por siempre la facultad legislativa de intervenir en materia laboral, esta facultad no puede ser absoluta. Ha de reconocer algún límite.

En efecto, nos basaremos en antecedentes históricos, sistemáticos y finalistas ${ }^{6}$ para desentrañar el alcance y sentido en el artículo $65 \mathrm{~N}^{\circ} 4$ de la Constitución, y concluiremos que no sería constitucionalmente admisible que el legislador determine protagónica e íntegramente el contenido de los elementos esenciales del contrato de trabajo. Las remuneraciones estarían en esta zona, la que solo puede ser alcanzada por la ley en forma supletoria al mecanismo primeramente llamado por la Constitución para definirlas: la voluntad de las partes, así expresada por pactos individuales o mediante el mecanismo de la negociación colectiva ${ }^{7}$.

Bajo este escenario, sostendremos que la atribución del artículo 65 numeral 4 de la Constitución, la libertad de trabajo y, en particular, el derecho a la libre contratación, deben ser interpretadas a la luz del conjunto de principios que emergen con la Constitución de 1980, especialmente las garantías establecidas en el llamado Orden Público Económico o Constitución Económica, en relación a las bases de la institucionalidad.

\footnotetext{
${ }^{5}$ La norma garantiza, en su inciso primero: "La libertad de trabajo y su protección". A su vez, en el inciso segundo garantiza que "Toda persona tiene derecho a la libre contratación y a la libre elección del trabajo con una justa retribución”.

${ }^{6}$ ZAPATA (2002) p. 48.

7 Al respecto, resulta ilustrativo el caso alemán, donde no existe regulación del salario mínimo. En Alemania, "Salario y jornada de trabajo están frecuentemente garantizadas por el convenio colectivo; en los "pactos por el empleo" empresariales se rebajarán a menudo las condiciones a cambio de una respuesta positiva del empresario sobre el mantenimiento de los puestos de trabajo, y para asegurar el empleo". Ver KOCHER (2007) p. 391. Sin embargo, este sistema ha suscitado problemas derivados de la competencia de costes salariales que la deslocalización de sede ha generado debido a las repercusiones trascendentales de la globalización sobre las normas laborales. Al respecto, el Tribunal Federal de Trabajo ha señalado que "un acuerdo que "vende" salario y tiempos de trabajo a cambio de asegurar el empleo, no constituye ninguna regulación favorable que sea admisible, reconociendo además, el derecho de oposición de los sindicatos contra dichos pactos empresariales, cuando dañan el convenio colectivo". KOCHER (2007) p. 392. Asimismo, "cada vez más los convenios colectivos incluyen cláusulas que permiten dichas regulaciones a la baja, cuando resulten necesarias para asegurar el empleo. Pero en estos casos de flexibilización del convenio colectivo sectorial con el objetivo de una descentralización controlada, las partes del convenio colectivo (también los sindicatos) deben consentir el descenso, y también pueden examinar por causa de ello la verosimilitud de la amenaza de deslocalización”. KOCHER (2007) p. 392.
} 


\section{GESTACIÓN Y OBJETIVO INICIAL DE LA LEY Nº 20.281}

El punto de partida de nuestro análisis se encuentra en la historia de la ley No 20.281. Este cuerpo legal buscó equiparar el sueldo base al ingreso mínimo, evitando así la incerteza semántica que acarreaba para los trabajadores el saberse trabajando con sueldos base muy bajos, que, sumados a los variables, necesariamente debían alcanzar el ingreso mínimo. El sueldo base -se afirmó- siempre debe equivaler al mínimo y el trabajador debe saber que nada le impedirá alcanzarlo, porque la ley se lo garantiza.

Hasta aquí, el proyecto de la ley No 20.281 no perseguía impactar las remuneraciones, sino solo cambiar sus denominaciones y estructuras, sin alterar sus montos. Ello porque siempre, aun antes de esta ley, ningún trabajador podría ser remunerado por menos del ingreso mínimo, cualquiera sea su sueldo base y su salario variable.

Empero, sorpresivamente entró a la discusión derivada del llamado beneficio de la "semana corrida", previsto en el Código del Trabajo para los trabajadores remunerados exclusivamente por día. Esta prebenda busca proveer a estos trabajadores el equivalente del día de descanso semanal, transformado en remuneraciones.

La cuestión se convirtió en el tema central del debate posterior a la promulgación de este cuerpo normativo, y con ello, del presente artículo ${ }^{89}$.

Revisemos entonces el origen del proyecto para indagar por los efectos del fenómeno.

${ }^{8}$ La recepción oficial de la iniciativa fue polémica desde la perspectiva de los gremios sindicales. Por ejemplo, con fecha 6 de agosto de 2008 dirigentes sindicales y trabajadores de la CGT mancharon desde calle Dieciocho con Alameda hasta la Dirección del Trabajo y el Ministerio del Trabajo para expresar su opinión respecto de la Ley 20.281. Véase http://www.defensadelcobre.info/modules.php?name=News\&file=print\&sid=4629. Tras la publicación de la ley, no han disminuido las apreciaciones negativas en torno a ella, así, en enero de 2009, el presidente de la CGT señalaba: "Para que la ley que hemos comentado sea efectivamente un avance deberemos peleársela al sistema. I.- Tenemos que demandar ante los organismos que corresponda una explicación respecto del criterio con el que se define el sueldo base, que en nuestra opinión no debe ser compuesto por un monto más bonos fijos, sino efectivamente el monto del ingreso minimo fijado por ley.

II.- Deberemos lograr que se establezca, sin duda alguna, que la diferencia de los variables no pueden sino ser resultado de los tratos o comisiones, para que efectivamente permitan el pago de la semana corrida. No podemos olvidar que está latente la conversión de esta diferencia en un bono fijo.

III.- Tendremos que realizar todas las gestiones necesarias para conseguir que se establezca, sin atisbo de duda, que el ajuste en caso alguno puede significar cambio en los contratos de trabajo, ya que existen leyes que regulan esta posibilidad y no han sido derogadas.

IV.- Tendremos que poner todo el esfuerzo en demostrar que cualquier cambio de factores en el "ajuste" irá en perjuicio de la remuneración, más allá de que antes y ahora sigan siendo los mismos montos". Véase http:// www.elojolaboral.org/?p=372.

${ }^{9}$ La Cámara de Comercio de Santiago dictaminaba en julio de 2008 que "El impacto de esta nueva ley será por partida doble. Como advirtió la CCS en una publicación anterior, extender el beneficio de la semana corrida hacia los trabajadores con remuneración mensual tendrá un costo del orden de US\$1.000 millones con claros efectos negativos sobre la competitividad de la economía chilena. En cuanto a la asimilación del sueldo base al salario minimo, significará elevar, por el solo hecho de esta ley, el universo de trabajadores que verá reajustado su ingreso, y que en la actualidad totaliza alrededor de 600 mil trabajadores. Al costo económico se agrega que esta normativa incentiva al empleador a preferir componer las futuras remuneraciones privilegiando el componente fijo en desmedro de la remuneración variable, desincentivando el uso de modelos que premian la productividad del trabajo". Véase http://www.ccs.cl/html/informe_economico_files/06\%20Ingreso\%20M\% C3\%ADnimo\%2008-06-09.pdf 
La ley $\mathrm{N}^{\circ} 20.281$ se origina en un proyecto de ley iniciado por el Ejecutivo, a través del Mensaje 731-355, titulado "Modificación al Código del Trabajo en materia de salarios base", de 21 de septiembre de 2007 (Boletín N5433-13-1).

El mensaje del Ejecutivo expresó con cierta confusión esta idea. El Presidente afirma que la iniciativa legal surge por la interpretación que han hecho "muchos sectores" de la redacción de los artículos 41 (noción de remuneración), 42 (componentes potenciales de la remuneración) y 44 inciso tercero (remuneración del trabajador no puede ser inferior al mínimo legal) del Código del Trabajo, que implica entender "que toda la remuneración del trabajador puede ser variable, en tanto esta no sea inferior a la minima legal" 10.

Del diagnóstico anterior es que surge la propuesta legal del Ministerio del Trabajo y Previsión Social que tiene por objetivo:

“(..) determinar que el sueldo base (...) no puede ser inferior al minimo legal, sin perjuicio que el resto de la remuneración se componga de elementos variables (...) en forma de incentivo (...) Para una correcta lectura e interpretación de la totalidad de los componentes de la remuneración, deben entenderse estos estrechamente ligados también a la totalidad de los componentes que integran la prestación de los servicios del trabajador a su empleador. Ello es evidente, ya que el contrato de trabajo se define sustancialmente como una prestación de servicios seguida de una contraprestación en dinero, no pudiendo definirse en su esencia jurídica sin la concurrencia de ambos elementos"11.

Para el Ejecutivo no cabe sino concluir que el sueldo o estipendio fijo que percibe el trabajador, corresponde al tiempo de prestación de sus servicios en la empresa, es decir "a la remuneración que tiene como correspondencia la prestación de los servicios en una jornada ordinaria pactada, dejando a otros elementos la compensación por la productividad del trabajador" 12 .

Así, para el Ejecutivo, si el sobresueldo es la contraprestación por una mayor jornada que la ordinaria (jornada extraordinaria), "forzoso es concluir que el sueldo es la contraprestación por los servicios dentro de la jornada ordinaria de trabajo" ${ }^{13}$.

10 Historia de la ley $N^{\circ} 20.281$, p. 5. A mayor abundamiento, para el Presidente de la República "El argumento en que se basa la señalada interpretación consiste en colegir que si el legislador señala expresamente en el artículo 44 del Código del Trabajo, que la remuneración como tal -con sus componentes fijos y variables- no puede ser inferior a la mínima legal, esta puede descomponerse, a su vez, también en elementos fijos y variables, o solo en estos o aquellos. Esto ha llevado a la aplicación de esquemas remuneracionales que no consideran la existencia de sueldo base o pactar "sueldos" (elemento fijo) de cantidades insignificantes $[\$ 1.000, \$ 10.000, \$ 20.000]$, estableciendo que el trabajador debe, mediante su productividad, completar en forma variable el complemento, hasta alcanzar un Ingreso Mínimo Legal. Dicha interpretación, a nuestro juicio, adolece de graves inconsistencias en el marco de la legislación general del Código del Trabajo y genera graves consecuencias patrimoniales a los trabajadores, a la vez que no permite contar con un concepto legal que sea reflejo del verdadero sentido y alcance que tiene la fijación de una remuneración mínima, o salario mínimo legal". HISTORIA DE LA LEY N² 20.281, p. 5.

${ }^{11}$ Historia de la Ley $N^{\circ} 20.281$, p. 6.

${ }^{12}$ Historia de la Ley $N^{\circ} 20.281$, p. 6.

${ }^{13}$ Historia de la Ley $N^{\circ} 20.281$, p. 6. 
El problema de fondo que describía el Mensaje del Proyecto era de naturaleza laboral, específicamente de estructura de remuneraciones. Consistía en la existencia de elementos variables al cálculo del Ingreso Mínimo Mensual, lo que al entender del Jefe de Estado "corresponde a una confusión conceptual que no tiene correspondencia con el espíritu del legislador al diferenciar los criterios variables y fijos de la contraprestación del empleador, ya que su percepción en forma segura y "fija" es un derecho que deriva del carácter obligatorio general del IMM y que, en definitiva, corresponde al sueldo base del trabajador por el cumplimiento de su jornada ordinaria de trabajo" 14 .

Es decir, el Presidente de la República estimaba que se había suscitado un problema en la estructura conceptual de las remuneraciones de los contratos de trabajo. El Jefe de Estado constataba que en la práctica existían remuneraciones variables en la zona por cuyos montos debiese estar cubierta por el ingreso mínimo. El problema parece obvio y sencillo, porque el artículo 44 del Código dispone que "El monto mensual de la remuneración no podrá ser inferior al ingreso minimo mensual".

Luego, parece natural que si el ingreso mínimo es obligatorio por el solo ministerio de la ley, las partes no podrían pactar que en ese tramo exista incerteza sobre su devengamiento.

Así, es natural lo que el Presidente señalara en cuanto a la "confusión conceptual”. Y la forma de repararlo sería reestructurando la denominación de las remuneraciones, reparando así una contradicción semántica (ingreso mínimo obligatorio - remuneración variable, incierta).

Asimismo, en la discusión en general del proyecto en segundo trámite constitucional, y como se desprende del Primer Informe de la Comisión del Trabajo y Previsión Social del Senado, se clarifica la opinión del Ejecutivo, a través de su Ministro del Trabajo y Previsión Social.

Esta opinión será fundamental para entender que el objetivo matriz y original de la ley fue solo igualar el sueldo base al ingreso mínimo legal, y no disponer el aumento de remuneraciones. Para el Ministro, esto último es un tema propio de la relación entre empleador y trabajador, y en este ámbito el proyecto no incidiría ${ }^{15}$.

Particularmente relevante fue el intercambio de opiniones posterior que se produjo en la Comisión entre los senadores miembros y el Ministro del Trabajo, en relación a clarificar cuáles son las cuestiones que perseguía el proyecto y cuáles no lo son ${ }^{16}$.

\footnotetext{
${ }^{14}$ Historia de la Ley $N^{\circ} 20.281$, p. 6.

15 Señaló el Ministro: "que el objetivo de la iniciativa legal es establecer que el sueldo base que recibe el trabajador, no podrá ser inferior al ingreso mínimo legal (...) Advirtió que, en ningún caso, se pretende generar por esta vía un mecanismo encubierto de mejoramiento de remuneraciones. Explicó que, justamente es por ello que el artículo transitorio del proyecto establece un plazo dentro del cual los empleadores deberán ajustar las remuneraciones de sus trabajadores a esta nueva exigencia legal. Se trata pues, de regularizar la situación y se ofrece al empleador un tiempo prudente para ello, pero ese período de ajuste no significa necesariamente dar lugar a un incremento remuneracional, sino solo permitir la adecuación pertinente según la modificación que se introduce (...) La mejoría en materia de remuneraciones, añadió, es un tema propio de las negociaciones entre empleadores y trabajadores, y en ese ámbito la iniciativa legal no incide". Historia de la Ley $N^{\circ} 20.281$, p. 32.

16 Ver especialmente pp. 34 y siguientes del Informe donde aparece el intercambio de opiniones entre el Ministro del Trabajo y los senadores Pérez Varela y Allamand.
} 
Con todo, y junto con lo anterior, buena parte del debate que generaría la ley No 20.281 estaría dado por la presentación por parte del Ejecutivo, en segundo trámite constitucional ante el Senado, en abril de 2008, de la indicación No 3 que propuso lo siguiente ${ }^{17}$ :

"Agrégase en el inciso primero del artículo 45, a continuación del punto aparte (.) que pasa a ser punto seguido (.), la siguiente oración: "Igual derecho tendrá el trabajador remunerado por sueldo mensual y remuneraciones variables, tales como comisiones o tratos; pero, en este caso, el promedio se calculará solo en relación a la parte variable de sus remuneraciones".

Al revisar la historia de la ley en lo referido a la Indicación, sorprende la simpleza del debate que acompaña a su presentación, contrastando con los efectos que produciría. Esto será relevante porque de las siete indicaciones presentadas, solo la referida $\mathrm{N}^{\circ} 3$, sobre extensión del beneficio del pago de la llamada "semana corrida"18 a trabajadores que antes no lo recibían, es la única que sería aprobada sin modificaciones en la Comisión y por la unanimidad de sus miembros.

\section{IMPACTO DE LA LEY N²0.281 SOBRE LAS REMUNERACIONES DEL SECTOR PRIVADO}

Luego de haber analizado la historia de la ley, corresponde escrutar si la ley No 20.281 ordena, impone o manda un aumento de remuneraciones para trabajadores del sector privado. Ello es de suyo relevante en la medida en que nos permitirá evaluar la legitimidad de la actuación del legislador tanto en el caso concreto como para la obtención de criterios futuros en la materia; como asimismo, para hacer frente a la pregunta ¿cuándo y bajo que parámetros resulta tolerable constitucionalmente un aumento legal de remuneraciones para el sector privado?

A nuestro juicio, es claro que la primera parte de la ley, esto es, aquella que equipara el sueldo base al ingreso mínimo ${ }^{19}$, no dispone un aumento de remuneracio-

17 La Indicación del Ejecutivo consta del Boletín de Indicaciones $N^{\circ} 5.433-13$, de 28 de abril de 2008. Historia de la ley No 20.281, p. 43.

${ }^{18}$ La ley No 20.281 alteró la lógica básica del beneficio de la "semana corrida", al extendérsele más allá de cómo fue originalmente concebido: un incentivo para trabajadores remunerados por día de trabajo, y no para aquellos que se les remunera por períodos mensuales. Para Humeres (2007) p. 176, esta antigua institución de nuestro derecho laboral "pretendía incentivar la asistencia al trabajo todos los días de la semana, evitando sobre todo la ocurrencia del denominado "San Lunes", que tanto daño ocasiona a ciertos sectores productivos". En idéntico sentido se pronuncian THAYER y NOVOA (1998). Desde la mirada de las políticas públicas, el pago de la semana corrida se origina "como un sistema de incentivos para asegurar que los trabajadores asistieran todos los días y recaía en aquellos trabajadores remunerados exclusivamente por día. Los trabajadores que habían trabajado de lunes a sábado recibían el pago de un séptimo día para premiarlos por haber cumplido y si faltaban algún día no lo recibían. Este sistema fue convenido para el sector agrícola, y tuvo un origen social, con el fin de desincentivar el alcoholismo". LIBERTAD y DESARROLLO (2008) p. 2.

${ }^{19}$ Numerales 1 y 2 del Artículo Único, en relación al Artículo Transitorio de la ley No 20.281. 
nes. Esta afirmación emerge si se atiende al artículo 42 del Código del Trabajo, a la historia de la ley $\mathrm{N}^{\circ} 20.281$ y al Dictamen de la Dirección del Trabajo que la interpre$\mathrm{ta}^{20}$. Estos preceptos equiparan jurídicamente "sueldo" a "sueldo base" y le hace aplicable a este último la frase vigente del artículo 42 a) del Código consistente en que " $n o$ podrá ser inferior a un minimo mensual'.

En esta parte, el ajuste ordenado por la ley No 20.281 es solo un cambio estructural y conceptual en la denominación de los salarios y su relación con la jornada ordinaria. Ello puesto que el pago del ingreso mínimo ha sido siempre obligatorio, independiente de su carácter fijo o variable. En los casos en que proceda dicho ajuste -trabajadores cuyo sueldo base es inferior al ingreso mínimo antes de esta ley- este se hará sobre la base de los emolumentos variables manteniendo la remuneración líquida total.

Distinto es lo que ocurre con la segunda parte de la ley. El numeral 3 del Artículo Único efectivamente produce un aumento real de remuneraciones a trabajadores del sector privado, al disponer el pago del beneficio del día semanal de descanso a trabajadores remunerados variablemente por mes, y ya no solo por día. Lo anterior altera estructuralmente las remuneraciones efectivas a que tienen derecho estos trabajadores, incrementándoselas. El efecto se produce al cambiar la lógica desde el trabajador remunerado variablemente por día, a aquel remunerado variablemente por mes. En esta última estructura, antes de la ley el día de descanso semanal ya se encuentra reflejado en el sueldo total mensual. Si se dispone el pago especial de ese día, aumenta el sueldo.

Con todo, los efectos -en términos de aumentos de costos- son distintos dependiendo de la actividad económica de que se trate y en consecuencia, del porcentaje de la remuneración que sea variable, que en el caso de trabajadores comisionistas suele ser muy alta; del sistema de turnos que utilice la empresa; del porcentaje de trabajadores de la empresa que cumplan con las condiciones para acceder al beneficio; entre otros ${ }^{21}$.

20 ORD N ${ }^{\circ} 3152 / 063$ de 25 de julio de 2008 que "Fija sentido y alcance de los artículos 42 a), 44 y 45 del Código del Trabajo, en el texto fijado por la ley $\mathrm{N}^{\circ} 20.281$ y del artículo transitorio de dicha ley". En especial véase página 8 con cuadro que ejemplifica la manera de realizar el ajuste y como no se afecta la remuneración líquida total del trabajador.

21 Además, mediante Dictamen Ord. No 3262/066 de 5 de agosto de 2008, la Dirección del Trabajo precisó que el beneficio de la semana corrida no se aplica para trabajadores que tienen una jornada de menos de 5 días de trabajo. Así, el aumento de costos medidos sobre la remuneración total (base + variable) de los trabajadores se produce en aquellos con jornada de trabajo de 5 y de 6 días a la semana. Así, en el caso de un trabajador cuyo porcentaje de remuneración variable es $60 \%$ y que trabaja 6 días a la semana, se produce un incremento en su remuneración igual al $10 \%$. La explicación del aumento de remuneraciones es la siguiente: el monto total a recibir por concepto de comisiones antes de la ley equivalía diariamente a un sexto del total. La ley No 20.281, al disponer que se debe pagar un séptimo día, implica que el trabajador recibe un sexto adicional de remuneración variable que antes no recibía, y no debe trabajar más para obtener este aumento en la remuneración variable. Es un aumento, además, sin contraprestación especial en servicios. Así, el efecto sobre la remuneración total dependerá del porcentaje de la remuneración que sea variable. Entonces, a mayor porcentaje variable, el efecto sobre la remuneración total será mayor. En el extremo, si el 100\% de la remuneración fuese variable, los trabajadores con un sistema de turnos 6-1 aumentarían su remuneración total en $1 / 6(16,66 \%)$, y aquellos con un sistema de turnos 5-2, en el extremo, aumentarían su remuneración total en un 20\%. Ver LiberTAD y DeSARROLLO (2008) 
Habiéndose determinando que la ley $\mathrm{N}^{\circ} 20.281$ efectivamente introdujo forzosamente un aumento de remuneraciones en los contratos de trabajo de los trabajadores del sector privado, surge otra interrogante: ¿qué clase de elemento del contrato son las remuneraciones? ¿Se trata de un elemento accidental de los contratos de trabajo, en términos de resultar plenamente lícito para la ley regularlo o alterarlo discrecionalmente? ¿O más bien se trata de uno de los elementos esenciales del contrato de trabajo, que es intangible a la ley? ¿O bien, solo puede ser alterado por el legislador excepcionalmente, en subsidio de la voluntad de las partes y del mecanismo de la negociación colectiva?

El Código del Trabajo (en adelante el Código o CT) contiene una definición precisa de contrato de trabajo, formulada como sigue en su artículo $7^{\circ}$ :

"Contrato individual de trabajo es una convención por la cual el empleador y el trabajador se obligan reciprocamente, este a prestar servicios personales bajo dependencia y subordinación del primero, y aquel a pagar por estos servicios una remuneración determinada". sual...".

Luego, el artículo $9^{\circ}$ del mismo código comienza "El contrato de trabajo es consen-

De estas dos citas del Código se desprende nítidamente que el contrato individual de trabajo tiene dos elementos: la prestación de servicios personales bajo dependencia y subordinación, y la remuneración, y que estos elementos deben determinarse fundamentalmente por el consentimiento de los contratantes, al definírsele por el Código como consensual, y sin perjuicio de la obligación de que conste "por escrito" 22 .

Por consiguiente, y a pesar de que el contrato de trabajo debe contener numerosas estipulaciones mínimas de acuerdo a la ley laboral ${ }^{23}$, la propia ley y la doctrina reducen a dos las indispensables y esenciales en lo dogmático: prestación de servicios bajo subordinación y dependencia, y remuneraciones.

El mismo Mensaje presidencial de la ley No 20.281 establece que el contrato de trabajo reconoce jurídicamente dos elementos esenciales:

“(...) el contrato de trabajo se define sustancialmente como una prestación de servicios seguida de una contraprestación en dinero, no pudiendo definirse en su esencia jurídica sin la concurrencia de ambos elementos. La falta o ausencia de cualquiera de ellos, implica que estamos en presencia de un acto jurídico de diversa naturaleza".

Ahora bien, ¿qué son las remuneraciones? Las disposiciones del primer Código del Trabajo hacían un distingo esencial en cuanto a las remuneraciones: salario se denominaba a la retribución del obrero y sueldo a la del empleado particular. Asimismo, las demás remuneraciones específicas y accesorias de ambas calidades recibían también un nombre distinto, aun cuando su causa fuera la misma análoga o parecida.

22 Artículo $9^{\circ} \mathrm{CT}$, inciso primero.

${ }^{23}$ Ver numerales $1^{\circ}$ al $7^{\circ}$ del artículo 10 del CT. 
Hoy en que el nuevo texto del Código no hace la distinción entre obrero y empleado, uniformando con la voz trabajador, es lógico que establezca para estos un solo tipo de remuneraciones. Para ello siguió el sistema que el Código indicaba para los empleados particulares ${ }^{24}$.

Dice el artículo 41 del Código del Trabajo que "se entiende por remuneración las contraprestaciones en dinero y las adicionales en especie avaluables en dinero que debe percibir el trabajador del empleador por causa del contrato de trabajo". Por su parte, el artículo 42 establece las principales remuneraciones: sueldo, sobresueldo, comisión, participación y gratificación.

Para la ley, todas las contraprestaciones al trabajador son consideradas como remuneraciones. Es decir, la esencia de este contrato alcanza a toda suma en dinero o prestaciones en especie avaluables en dinero que se paguen al trabajador por sus servicios. En este sentido, no hay remuneraciones esenciales y remuneraciones accidentales; todas son remuneraciones por igual, como elemento básico del contrato.

De lo anterior se concluye que el contrato de trabajo reconoce dos elementos esenciales sin los cuales derivaría en otro distinto: los servicios bajo subordinación y dependencia y la remuneración. Se infiere también del Código que es voluntad del legislador que estos elementos esenciales sean primordialmente definidos por el consentimiento de los contratantes, esto es empleador y trabajador. De lo contrario, la ley no habría calificado al contrato de trabajo como consensual.

No obstante, es natural que debamos reconocer un cierto margen al legislador para definir los parámetros bajo los cuales un contrato de trabajo debe ser celebrado. Ello emana del principio general de la regulación y complementación por ley de los derechos constitucionales, según lo establecido en el artículo 19 numeral 26 de la Carta Máxima, y especialmente del significado de la expresión constitucional de la "justa retribución”, que la Constitución asegura a todas las personas, junto con su derecho a la libre contratación, en el numeral 16, inciso segundo, del mismo artículo.

Así las cosas, la tarea siguiente consiste en determinar con precisión cuál es ese margen o ámbito constitucionalmente lícito de la ley en la regulación del contrato de trabajo o en la determinación de sus parámetros esenciales, que resulte compatible con la libertad de contratación.

\section{DERECHO A LA LIBRE CONTRATACIÓN Y POTESTADES LEGISLATIVAS SOBRE AUMENTOS DE REMUNERACIONES PRIVADAS}

Se buscará aquí identificar el núcleo o esencia del derecho constitucional a la libre contratación con una justa retribución, así como el rol que la Carta Fundamental asigna a "la negociación colectiva con la empresa que laboren", como derecho de los trabajadores ${ }^{25}$.

\footnotetext{
${ }^{24}$ Humeres (2007) p. 175.

25 Artículo $19 \mathrm{~N}^{\circ} 16$, inciso quinto, CPR.
} 
Revista Chilena de Derecho, vol. 37 Nº 2, pp. 343- 376 [2010]

Fermandois V., Arturo \& García G., José — "Compatibilidad entre el derecho a la libre contratación y la fijación..."

\subsection{El DERECho A LA libre CONTRATACión. ORIGEN y CONTENido CONSTITUCIONAL}

La garantía contemplada en el numeral 16 del artículo 19 de la Constitución Política ha sido normalmente estudiada en cuanto a los trabajos lícitos y los trabajos prohibidos, esto es, en cuanto a la libre elección de un trabajo u oficio ${ }^{26}$. Pero poco se ha reflexionado sobre el contenido de la segunda parte, aquella que apunta a la autonomía contractual, esto es, a la facultad de trabajador y empleador de contratar.

La libertad de trabajo reconoce su origen histórico en Chile en el antiguo artículo 142 (151) de la Constitución de 183327. Para Irureta, tanto la Constitución de 1925 como la de 1980, consagraron esta norma en el entendido que "con ella se permitía una amplia facultad de la persona para buscar, obtener, ejecutar, desempeñar o desarrollar cualquier actividad que recayera dentro de la licitud del marco legal" 28 .

Por su parte, Verdugo y Pfeffer reconocen que el estudio del precepto actual en la Carta de 1980 se dificulta por cuanto el material contenido en las actas de la Comisión de Estudio para la nueva Constitución (CENC), que en lo que atañe a esta materia, "no resulta muy ilustrativo". Por otra parte, para estos autores contribuye a dificultar el análisis el que la proposición de la CENC fuera objeto de importantes modificaciones posteriores, tanto por parte del Consejo de Estado como por la Junta de Gobierno ${ }^{29}$.

Con todo, al menos queda claro que se trató de diferenciar del "derecho al trabajo” establecido en la Constitución de 1925. Jaime Guzmán, miembro de la CENC, fue persuasivo al sostener que al establecer un "derecho al trabajo" más bien se estaría apuntando a una "aspiración programática" 30.

\footnotetext{
${ }^{26}$ La norma garantiza, en su inciso primero: "La libertad de trabajo y su protección". A su vez, en el inciso segundo garantiza que "Toda persona tiene derecho a la libre contratación y a la libre elección del trabajo con una justa retribución".

27 IRURETA (1992) pp. 491-92.

28 IRUReTA (1992) p. 492. Para el autor: "Fue recién en 1971, con la dictación del llamado Estatuto de Garantías, que se incorporan a la Constitución derechos tan importantes como el derecho al trabajo, de sindicación, derecho de huelga y de seguridad social, entre otros. Fue justamente con esta reforma que se incorporó un inciso de un tenor similar al actual número 16: "La Constitución asegura a todos los habitantes: la Libertad de trabajo y su protección”. IRURETA (1992) p. 492.

${ }^{29}$ Verdugo y PFeFFer (2005) p. 281.

${ }^{30}$ En la sesión 194 del 25 de marzo de 1976 sostuvo que: "Sus razones se basan en que si se repara en la redacción del precepto, se apreciará que cuando se habla de que una persona tiene "derecho al trabajo", se está también apuntando a una aspiración programática, en cierto modo, porque en un país donde hay cesantía es evidente que tal derecho no les está reconocido a determinadas personas. Estima que la cesantía -en la actualidad, más alta que en otras épocas de la historia de nuestro país y de otros lugares del mundoes, sin embargo, en porcentaje relativamente significativo, una realidad contemporánea de todas las naciones. De modo que la inquietud surgida aquí respecto de la parte final del precepto, pretende llevarla a la parte inicial del mismo, pues ya no solamente podría darse el caso de alguien que recurriera a los tribunales a sostener que estos deben directamente concederle la justa participación en los beneficios que provengan de su actividad, sino que podría recurrir a ellos por algo mucho más elemental, como es para decir que está sin trabajo; que la Constitución le garantiza el derecho al trabajo y la facultad de ocurrir ante los tribunales para que sus derechos sean resguardados, y que se arbitren los medios para que efectivamente este derecho le sea respetado, lo cual, obviamente, desborda las posibilidades de acción de los tribunales". CENC (1976) p. 21
} 
Como decíamos, los autores se concentran casi exclusivamente en el problema de los trabajos prohibidos y autorizados, y en su justa retribución. Para Evans, por ejemplo, la libertad de trabajo y su protección es un derecho constitucional que:

"habilita a toda persona a buscar, obtener, practicar, ejercer o desempeñar cualquier actividad remuneratoria, profesión u oficio licitos, vale decir, no prohibidos por la ley. Esta garantía implica, además, el derecho a la libre contratación (...) la garantía culmina con el derecho de elegir trabajo con entera libertad y con acceso a una justa retribución (...) El contenido esencial de esta garantía asegura que a nadie le será impuesto un trabajo o un trabajador; que a nadie le será negado un trabajo por razones arbitrarias y que quien trabaje lo haga con una justa retribución (C.E.N.C., Sesión 199, de 7 de abril de 1976, págs. 13 a 17)"31.

Recién con ocasión de la Ley de Subcontratación ( $N^{\circ} 20.123$, de 2006), la doctrina repara con más detención en la libre contratación. Es el caso de Ribera Neumann, para quien la expresión "toda persona tiene derecho a la libre contratación" a que se alude en el inciso segundo del artículo 19 numeral 16 de la Constitución, apunta a la libertad esencial de contratar o no contratar (trabajadores), sin apremios al respecto.

“(...) se refiere a la libertad de cada cual, dentro del marco fundamental de la no discriminación arbitraria, de celebrar un acuerdo laboral sometido a las normas legales. Lo anterior significa que nadie puede ser obligado a contratar trabajadores contra su voluntad (...) Igualmente, desde el punto de vista del trabajador, comprende el derecho a no imponérsele un empleador, sea este una persona natural o jurídica, diverso de aquel con el cual se ha contratado, pues el vínculo laboral conlleva siempre un derecho a elección, el que debe ser respetado"32.

De manera que, luego de la experiencia de la ley de subcontratación en 2006 y sin perjuicio de la intensa regulación legal, debemos que admitir existe un indiscutible núcleo de libertad en la esencia del contrato que trabajador y empleador $\operatorname{pactan}^{33}$. No sería admisible que el legislador determine íntegramente el contenido del contrato de trabajo, o, como dice Silva Bascuñán, "imponga escalas o pautas de remuneraciones" 34 .

\footnotetext{
${ }^{31}$ Evans (1999) pp. 10 y 11. En la sesión 195, de 30 de marzo de 1976, la CENC escuchó al Ministro del Trabajo y Previsión Social, don Sergio Fernández: “(...) considera que es deber del Estado, y debiera consagrarlo la Constitución, establecer el derecho que todos los trabajadores, todos los chilenos, tienen al trabajo, aun cuando la satisfacción de este derecho es función del Estado. Estima que aquí es donde, en definitiva, el Estado tiene un campo de acción fecundo: la creación de los medios e instrumentos necesarios para dar trabajo; no darlo como estado en sí, sino crear las condiciones para que, en definitiva, se pueda ejercer este derecho". EVANS (1999) p. 42.

32 Ribera (2007) p. 285.

33 Recuérdese que el Tribunal Constitucional declaró inconstitucional (2006) la nueva definición de empresa del proyecto de ley de subcontratación, que excluía de ella la individualidad legal determinada.

34 Silva BASCUÑÁN (1970) p. 81.
} 
Como sostiene Cruz-Coke la CENC vinculó estrechamente la libertad de trabajo con la libertad económica, desarrollando ambas garantías aspectos del Orden Público Económico: "Después de haberse consagrado la libertad de trabajo en el No 16, parecía redundante reiterar este derecho en relación con las actividades económicas, pero la Comisión de Estudio estimó necesario consignarla a fin de evitar que en el futuro se pudiere obstruir la libertad económica, como aconteció en un pretérito presente" 35 .

El mismo sentido lo concibe Irureta, quien plantea que la libertad de trabajo debe contextualizarse bajo la nueva Constitución Económica, y en armonía con el derecho a desarrollar cualquier actividad económica:

“(...) podemos advertir una verdadera Constitución económica que intenta determinar el papel que le cabe al estado y los particulares en la regulación de la economía y el bienestar del pais. (...) La libertad de trabajo no es una garantía aislada. Se nutre de diversos elementos $y$, a pesar que son preceptos con una orientación diversa, no cabe duda que la garantía del $N^{\circ} 21$ se entremezcla estrechamente con la posibilidad de buscar, obtener, practicar, ejercer o desempeñar cualquier actividad remunerativa, profesión u oficio lícito"36.

Así las cosas, la libre contratación no es una norma que deba ser interpretada como una garantía aislada, al decir de Irureta. Debe, por el contrario, concordarse con el conjunto de principios que emergen con la Constitución de 1980, especialmente las garantías del artículo 19 que conforman el llamado Orden Público Económico en relación a las bases de la institucionalidad. Aquí tiene especial relevancia el principio de subsidiariedad, en cuya virtud el Estado no debe asumir tareas, actividades o empresas que pueden ser cumplidas o ejecutadas adecuadamente por los particulares ${ }^{37}$.

\subsection{LA JUSTA RETRIBUCIÓN: CONCEPTO, DETERMINACIÓN E INGRESO MÍNIMO}

También resulta relevante para nuestros propósitos indagar por la frase constitucional asociada a la libertad de trabajo, aquella de “...con una justa retribución...”. Si esa frase autoriza una gran intervención de la ley en las remuneraciones, la ley 20.281 podría entenderse constitucional de fondo; de lo contrario, el aumento de remuneraciones para el sector privado sería una contravención a la Carta Fundamental.

El constituyente exigió que tanto la libre contratación como la libre elección contaran con un elemento adicional: la justa retribución. En este caso, la Constitución varió el criterio que tenía la Constitución de 1925 cuando hablaba de "remuneración suficiente". El actual inciso primero del numeral 16 del artículo 19 de la Carta Funda-

\footnotetext{
35 CRUZ-COKE (2005) p. 113.

36 IRURETA (1993) pp. 40-41. Asimismo, para YrarráZAVAL (1987) p. 100: "Es indiscutible que la libertad económica no es sino una manifestación de la libertad de las personas en general. Aplicación del principio la encontramos en el derecho a desarrollar cualquier actividad económica (...) y la libertad de trabajo".

37 Profundizadas en FERMANDoIs (2006). Otros autores que vinculan la garantía de la libertad de trabajo al orden público económico y/o a la libertad económica: GUERRERO (1979), YRARRÁZAVAL (1987), IRURETA (1992) y (1993), FERRADA (2000) y (2003) y CRUZ-COKE (2005).
} 
mental se refiere al término "justa retribución” que para Cea es "un concepto elástico, pero cuyo propósito es nítido, esto es, que la retribución al trabajador debe ser suficiente para asegurarle a él y a su familia, un nivel de satisfacción de sus necesidades y aspiraciones a una vida mejor que sea coherente con la dignidad de la persona humana" 38 .

Manifestaba el Comisionado Silva Bascuñán en la Comisión de Estudios de la Nueva Constitución en esta materia:

"que la frase tiene toda la ponderación de una solución muy ecuánime y justa. Agrega que, desde luego, la referencia a la palabra "justicia” en una problemática tan compleja no puede menos de estar condicionada a las posibilidades de una sociedad en un momento dado, y le parece que, además, es indiscutible, en principio y en la práctica, que las fórmulas destinadas a satisfacer estas aspiraciones del constituyente son muy diversas" 39 .

Este inciso sufriría algunas modificaciones, tanto en el Consejo de Estado como en la redacción final que le dio la Junta de Gobierno. En efecto, el inciso aprobado por la Comisión Ortúzar establecía que la justa retribución de una persona debía asegurar a ella y su familia, a lo menos, un bienestar acorde con la dignidad humana. El Consejo de Estado suprimió la frase final, dejando el inciso de la siguiente manera: "Toda persona tiene derecho a la libre elección del trabajo y a una justa retribución”. Finalmente, la redacción sometida a plebiscito agregó la frase referida a la libre contratación y cambió la conjunción "y" que antecede a la expresión justa retribución, por la preposición "con" 40 .

Todos estos cambios y evoluciones en el texto tuvieron por objeto configurar a la justa retribución como un derecho social, lato sensu, y no un derecho stricto sensu. En efecto, los constituyentes pensaban que esta clase de derechos no era garantizable simplemente con leyes, mediante decisiones que produzcan un disfrute instantáneo del derecho, sino que su disfrute era progresivo, de acuerdo a la capacidad económica del país.

Así, parece ir tomando forma la idea de que las remuneraciones son parte de la esencia de un contrato de trabajo, y por tanto materia propia de negociación entre trabajadores y empleadores.

El diseño de la Constitución Política así lo ha ratificado, sintonizando la libertad de contratación en un marco más amplio de Orden Público Económico, que no tan solo está preocupado del conjunto de regulaciones que le son permitidas al legislador; sino que de salvaguardar un margen razonable de libertad para los individuos.

Por lo demás, ello va de la mano con una mirada moderna respecto de cómo funcionan los mercados - lo más libres posibles para alcanzar la eficiencia asignativa y productiva-, lo que implica que la intervención del Estado en la economía se admite

\footnotetext{
38 CEA (2004) p. 428.

39 CENC, Sesión 194, de 25 de marzo de 1976.

${ }^{40}$ IrURETA (1992) p. 500.
} 
solamente en presencia de las denominadas fallas de mercado, y siempre que la intervención del Estado resulte más beneficiosa que tomar otro tipo de acciones ${ }^{41}$.

Sin perjuicio de ello, la Constitución también recoge una tradición de larga data de la legislación laboral en una materia que debe armonizarse con los criterios más libertarios de la Carta de 1980: asegurar ciertos salarios mínimos para los trabajadores.

Esta armonización va de la mano con la experiencia comparada, la que muestra que incluso en países de Europa -para algunos sinónimo de mercados laborales más rígidos y en donde el Estado juega un rol relevante en la fijación de precios de la mano de obra-, la evidencia es mixta ${ }^{42}$.

Es aquí donde se conecta salario mínimo con una justa retribución -que más allá de las discusiones normativas a que hemos hecho referencia, por ejemplo, de Cea-, se ha materializado en el establecimiento de un ingreso mínimo y de ciertas condiciones básicas (seguridad social, accidentes, etc.). Para esto el legislador cuenta con las atribuciones conferidas en el artículo $65^{\circ}$, que deben ser usadas en armonía con los principios inspiradores de la Constitución.

Estamos ahora en condiciones de analizar, de manera más detallada, cómo ha operado y opera la institución del ingreso mínimo, que es la invocada por la ley No 20.281 al igualarlos con los sueldos base.

\subsection{LA DETERMinACiÓN LEGAL DEL ingReSO MÍNIMO. CONSTITUCiÓn DE 1925 Y CONSTITUCIÓN DE 1980}

Las reflexiones anteriores apuntan que la justa retribución es un objetivo complejo e integral: el Estado no lo asegura directamente como derecho stricto sensu, sino debe

\footnotetext{
${ }^{41}$ Ver por ejemplo, desde una perspectiva jurídica, VALDÉS (2006), ROMERO (2008) y GARCía (2009); y, desde una perspectiva económica, LARROULET y MOCHÓN (1995).

42 En la gran mayoría de los países de Europa, el salario mínimo mensual se fija por el gobierno, generalmente después de consultar con las fuerzas sociales y se expresa en la legislación de cada país. En 2005, existía la figura del salario mínimo en 18 de los 25 países que integran la Unión Europea (Bélgica, República Checa, Estonia, Grecia, España, Francia, Irlanda, Letonia, Lituania, Luxemburgo, Hungría, Malta, Holanda, Polonia, Portugal, Eslovenia, Eslovaquia y Reino Unido), y en los tres países candidatos (Bulgaria, Rumanía y Turquía). Entre estos países, el salario mínimo en enero de 2005, varía desde los 72 euros de Rumania hasta los 1.467 euros de Luxemburgo; en Estados Unidos el salario mínimo federal se encuentra en 666 euros, aunque un número determinado de Estados tiene un salario mayor. Si se convierte el salario mínimo en una unidad de medida comparativa, Paridad de Poder de Compra o PPS, que libere del efecto del nivel de precios, la posición en el ranking de los diferentes países no varía, pero sí se ven reducidas sus diferencias. Así por ejemplo entre los países de la Unión Europea, el salario mínimo en euros oscila desde los 116 euros de Letonia y los 1.467 de Luxemburgo, lo que representa un factor de 1 a 13; mientras que si se analiza en PPS, la oscilación se registra entre los 283 y 1.293 , lo que representa un factor de 1 a 5. En el período 1999-2005, para los países que poseen información completa, el incremento, medido en euros ha ido desde el 13\% (Bélgica) hasta el 44\% (España); mientras que si se presenta en términos de PPS, el incremento oscila entre el 9\% (Luxemburgo) y el 43\% (Reino Unido). Bélgica, Francia y Reino Unido, en este período de cinco años, han visto como su incremento en PPS era superior al del euro; por el contrario en España, Luxemburgo, Holanda y Portugal el incremento en euros es mayor. En Grecia el incremento en euros y PPS es similar. En Estados Unidos, para el mismo período, el salario mínimo ha disminuido tanto en euros $(-12,6 \%)$ como en PPS $(-2,8 \%)$. Véase http://www.madrid.org/ iestadis/fijas/efemerides/ue220805.htm
} 
proveer el marco jurídico y económico para que trabajador y empleador lo pacten y alcancen. En este sentido, la justa retribución se conecta con la expresión "solución justa y pacifica" como objetivo constitucional de la negociación colectiva, instituto, que como sabemos, está contemplado también en el numeral 16 del artículo 19 de la Carta Fundamental.

Esto permite concluir que el ingreso minimo a que se refiere el Mensaje de la ley No 20.281 no es equiparable constitucionalmente a la justa retribución del trabajo. Mientras el ingreso mínimo es una decisión del Estado (legislador) sobre la retribución básica como límite inferior aceptable para todos los trabajadores, la justa retribución es algo más integral, y será determinada por la voluntad de las partes del contrato de trabajo, sea mediante negociación colectiva o negociación individual. Para esta última, la decisión del legislador es estrictamente excepcional y supletoria.

Para referirnos al ingreso mínimo, debemos volver sobre al artículo $65 \mathrm{~N}^{\circ} 4$ de la Carta Fundamental, que detalla dentro de la iniciativa económica exclusiva del Presidente la materia consistente en "fijar las remuneraciones minimas de los trabajadores del sector privado...".

Es decir, es indiscutible que la Constitución faculta a la ley la determinación del llamado ingreso mínimo, hoy en el artículo 44 del Código del Trabajo. Ahora bien ¿cuál es el origen histórico de esta atribución?

Desde una perspectiva jurídico-económica, el salario mínimo forma parte de la institucionalidad de los mercados laborales desde comienzos del siglo $\mathrm{XX}^{43}$.

En 1928, la OIT formuló su primera normativa internacional con el objetivo de regular su fijación. En efecto, como narra Gaete en su Tratado de Derecho del Trabajo y Seguridad Social de 1967:

"La Conferencia Internacional del Trabajo en su Undécima Reunión celebrada en Ginebra en 1928, adoptó el Convenio $N^{\circ} 26$, sobre instituciones de métodos para la fijación de salarios minimos -aprobado por Chile, el 18 de abril de 1933-, por el cual se obligan a los Estados ratificantes "a establecer o conservar los métodos que permitan la fijación de tipos minimos de salarios para los trabajadores empleados en las industrias o partes de industrias en las que no exista un régimen eficaz para la fijación de los salarios, por medio de contratos colectivos, u otro sistema, y en que los salarios sean excepcionalmente bajos" 44 .

Así, desde sus inicios, pese al carácter eminentemente interventor del Estado en el mercado laboral, el salario mínimo nace con caracteres propios de un instituto de natu-

\footnotetext{
43 Para Marinakis, la aplicación del salario mínimo ha tenido distintos objetivos en las últimas décadas. En los 60 y 70 se utilizó como instrumento contra la pobreza, reducción de las desigualdades de ingresos y como política macroeconómica. Durante los 90, la liberalización de los mercados y apertura de los mercados de bienes y servicios y financieros, llevó a proponer la debilitación o definitivamente la eliminación del salario mínimo". Ver MARINAKIS (2006).

${ }^{44}$ GAETE (1967) p. 180.
} 
raleza más bien excepcional ${ }^{45}$, supletoria y, en donde muchas veces, siguiendo a Thayer, la realidad económica relativiza dicho instrumento ${ }^{46}$.

De especial interés, continúa Gaete, es la Recomendación ํo 30 de la OIT, concerniente a la aplicación de los métodos para fijación de salarios mínimos, aprobada en la Conferencia Internacional del Trabajo de 1928. Esta recomendación dispone que en la fijación de los salarios mínimos hay que considerar un nivel de vida suficiente, o sea, que los salarios mínimos aseguren a los trabajadores la satisfacción de sus necesidades primordiales; y, salarios que se paguen para trabajos similares en las industrias en que los trabajadores se hallan suficientemente organizados, y han llegado a concertar contratos colectivos eficaces, de no tenerse este término de comparación, deberán inspirarse en el nivel general de salarios en el país o la localidad respectivos ${ }^{47}$.

Como sostiene Humeres, en la antigua legislación no había respecto de los obreros una remuneración mínima fijada en dinero, sino que el artículo 44 del Código de 1931 decía que era aquel no inferior a los dos tercios ni superior a los tres cuartos del salario normal o corrientemente pagado en la misma clase de trabajo, a los obreros de las mismas aptitudes o condiciones, en la ciudad o región en que se ejecute, y para determinarlo se consideraba la creación de comisiones mixtas o paritarias de patrones y obreros, presididas por el inspector del trabajo provincial o por el gobernador en los departamentos ${ }^{48}$.

Posteriormente, según Gaete, la Dirección General del Trabajo estimó en el Dictamen $\mathrm{N}^{\circ} 3501$, de $1^{\circ}$ de abril de 1944, que los obreros tendrían derecho a exigir el salario mínimo que se haya fijado, aunque hayan contratado bajo la vigencia de un salario mínimo inferior. Y en dictamen $\mathrm{N}^{\circ} 11.097$, de 28 de octubre del mismo año, la Dirección sostuvo que el tarifado mínimo tendría fuerza obligatoria si ha sido fijado en conformidad a la ley; para el caso de que con posterioridad a un fallo arbitral, en vigencia, se fije un salario mínimo superior al que señala dicho fallo, el patrón debe ajustar las remuneraciones de acuerdo con el tarifado ${ }^{49}$.

Respecto de los empleados particulares, en cambio, estos no podían percibir una remuneración inferior al sueldo vital del respectivo departamento, beneficio establecido por la ley $\mathrm{N}^{\circ} 7.295$, de 22 de octubre de 1942, y que fue derogado expresamente por la

45 Como sostiene MontT citado por Ferrada (2000) p. 49: "Los medios de intervención que utilice el Estado deben ser conformes al mercado y las técnicas del orden público económico, consistentes en la determinación del contenido de los contratos y la formación del vínculo contractual por vía de la autoridad, solo son admisibles por vía excepcional".

46 El concepto de ingreso mínimo preferido al de salario mínimo o vital es inobjetable y señala, en concordancia con el art. 23 No 3 de la Declaración Universal de Derechos Humanos, la obligación de la comunidad de contribuir a asegurar al trabajador el nivel mínimo de retribución que su dignidad humana exige y que a veces la empresa no está en condiciones de otorgar. Con todo, ha sido un hecho ostensible, ciertamente vinculado a las graves coyunturas de recesión y desempleo, la congelación relativa del monto del ingreso mínimo, la supresión en grado variable de la indexación de las remuneraciones y la lamentable frustración de la excelente iniciativa del "trabajo mínimo asegurado" que consagraron los artículos 13 y 14 del D.L. 603 de 10 de agosto de 1974 y que nunca se puso en vigor". THAYER (1985) p. 450.

47 THAYER (1985) p. 450.

48 En esta parte seguimos a HUMERES (2007) p. 178.

${ }^{49}$ GAETE (1967) p. 181. 
ley $\mathrm{N}^{\circ} 18.018$, de 14 de agosto de 1981 , en su artículo $6^{050}$. En aquellos tiempos la remuneración mínima provenía de los convenios colectivos o de las resoluciones de las comisiones paritarias o tripartitas ${ }^{51}$.

Pero luego de este desarrollo histórico surge la duda acerca de, entonces, cuál es el monto del salario mínimo mensual.

Humeres cree que hay que remontarse a la ley $\mathrm{N}^{\circ} 12.006$, de 23 de enero de 1956, llamada Ley de Congelación, que suprimió toda clase de reajustes para los prestadores de servicios, salvo los reajustes por años de servicios o antigüedad de los empleados particulares. Allí pretendió el legislador, al congelar remuneraciones y precios, estabilizar las remuneraciones, señalando que el sueldo vital y los jornales serían los mismos del año anterior más un 50\% del alza del costo de la vida determinado por el Banco Central y el Servicio Nacional de Estadísticas, llamado en aquella época Dirección de Estadísticas y Censos ${ }^{52}$.

Esta ley, que quiso terminar con la inflación en aquella época (atribuida al alza anual del sueldo vital y reajustes de los trabajadores), no dio el resultado apetecido y, así, año a año el legislador fue dictando nuevas leyes, a veces especiales, otras generales, o bien leyes misceláneas, por las cuales se vio obligado a conceder aumentos automáticos para paliar los aumentos de precios y tratar de aliviar la situación de los trabajadores sujetos a una cantidad congelada ${ }^{53}$.

A modo de ejemplo, cuenta Gaete, se ubica la Ley $\mathrm{N}^{\circ} 15.141$ de 19 de enero de 1965, que en su artículo 31 disponía:

"Los obreros que no estén sujetos a convenios colectivos, actas de avenimiento o fallos arbitrales y cuyas remuneraciones no excedan de cinco salarios minimos, tendrán derecho a percibir un aumento en sus jornales, igual al monto del aumento que corresponda al respectivo salario minimo y que se pagará conforme a las normas generales que le sean aplicables" 54 .

Esta política de reajustes periódicos continuó con posterioridad a 1973, donde incluso se amplió a otros tipo de ingresos (por ejemplo, salarios de obreros agrícolas) y beneficios (pensiones), de acuerdo al IPC 55 .

\footnotetext{
${ }^{50}$ Como sostiene Thayer: "Especialmente después de la llamada ley rastrillo (No 18.018 de 14 de agosto de 1981) se dio gran aliento a la iniciativa privada, se redujo la intervención del Estado en el mundo empresarial y laboral y se amplió la libertad en todas sus formas, que inspira la economía social de mercado. Después de ella pasó a ser más fácilmente legítimo que antes el desempeño de cualquier actividad empresarial o laboral, sin tantos requerimientos de afiliaciones gremiales, carnés profesionales, $u$ otras exigencias que entraban el derecho de emprender, contratar y trabajar". THAYER (1994) p. 21.

${ }^{51}$ Humeres (2007) p. 178.

52 Humeres (2007) p. 178.

53 Humeres (2007) p. 179.

54 GAETE (1967) p. 183.

55 Sostiene HUMERES, en una síntesis histórica de la evolución de esta legislación "Podemos contar veintiuna entre la $\mathrm{N}^{\circ} 12.401$, de 19 de diciembre de 1956 y la $\mathrm{N}^{\circ} 17.828$, que fijó el último reajuste para el periodo 1 de octubre de 1972 al 30 de septiembre de 1973 (...) Después del 11 de septiembre de 1973 se siguió un camino parecido al anterior. El Decreto Ley No 275, de 18 de enero de 1974 estableció ya en
} 
Finalmente, destaca como hito en esta materia, la nueva legislación previsional, fruto del DL $\mathrm{N}^{\circ}$ 3.500, de 13 de noviembre de 1980, conocido como de la Reforma Previsional. La reforma implicó que el legislador dispusiera en el DL No 3.501, de 18 de noviembre de 1980, un incremento en un 20\% del ingreso mínimo, con el objeto de mantener el monto total líquido de las remuneraciones que serían sometidas a descuentos previsionales. Desde entonces se distinguen dos ingresos mínimos: a) con incremento, $\mathrm{y} \mathrm{b)} \mathrm{sin} \mathrm{incremento,} \mathrm{los} \mathrm{que} \mathrm{han} \mathrm{sido} \mathrm{reajustados} \mathrm{desde} \mathrm{la} \mathrm{ley} \mathrm{N}^{\circ} 18.018$ de 14 de agosto de 1981 -cuando el ingreso mínimo era de \$ 5.458, 64- hasta la ley $\mathrm{N}^{\circ} 20.279$, vigente a contar del 1 de julio de 2008 que establece un ingreso mínimo de $\$ 159.000$.

De los antecedentes históricos y legislativos reseñados, se desprende que el reajuste del sueldo o ingreso mínimo está conectado desde sus orígenes directamente con la inflación y su impacto en las remuneraciones. El ingreso mínimo también fue esporádicamente usado para mantener automáticamente atado el reajuste de los salarios privados en general -y no solo del ingreso mínimo- ante el alza del costo de la vida, aunque ello no ocurre desde 1982, desencadenó gran polémica y para muchos, la crisis económica más grave de los últimos 30 años en Chile ${ }^{56}$.

Por consiguiente, puede concluirse que los trabajadores y empleadores del sector privado pueden prever y hasta esperar un reajuste relativamente periódico del ingreso mínimo, conforme ha ocurrido en el pasado. Este reajuste previsible debe estar conectado con parte del alza del costo de la vida; no resulta constitucionalmente previsible que las leyes ordenen aumentos que vayan más allá de la inflación, como tampoco que ordenen alzas a sueldos que no son el mínimo. Ello repugnaría al principio constitucional de la legítima confianza ${ }^{57}$.

Esta es una primera forma de interpretar la existencia de dos frases en el artículo $65 \mathrm{~N}^{\circ} 4$ de la Constitución: "fijar las remuneraciones minimas de los trabajadores del

forma expresa un ingreso mínimo mensual de $\mathrm{E}^{\circ}$ 18.000; el decreto Ley $\mathrm{N}^{\circ}$ 670, de 2 de octubre de 1974, viene a establecer ya no en forma ocasional sino en forma permanente, orgánica y completa un sistema de reajuste no solo del ingreso mínimo, sino del sueldo vital, salarios de obreros agrícolas, trabajadores de casas particulares y reajustes de pensiones y demás asignaciones y bonificaciones, agregando que este reajuste automático se otorgará de acuerdo al Índice de Precios al Consumidor (IPC), determinado por Instituto Nacional de Estadísticas (INE). (...) Siguen diversas disposiciones -Decretos Leyes que entre 1974 y 1997 van reajustando el salario mínimo- otros decretos leyes que conceden aumentos en proporción al aumento del costo de la vida según lo fije el INE (por ejemplo, DL 1.770, de 5 de mayo de 1977; $\mathrm{DL} \mathrm{N}^{\circ}$ 2.072, de 22 de diciembre de 1979; DL N³.529, de 6 de diciembre de 1980; $\mathrm{DL} \mathrm{N}^{\circ} 3.625$, de 21 de febrero de 1984; Ley $\mathrm{N}^{\circ} 18.018$ de 14 de agosto de 1981; Ley $\mathrm{N}^{\circ}$ 18.073, de 1 de diciembre de 1981; y las $\mathrm{N}^{\circ} 18.224,18.382,18.478,18.573$ y 18.647)". HUMERES (2007) pp. 179-180.

56 Para Harberger, a la sazón Profesor del Departamento de Economía de la Universidad de Chicago: "la crisis de la devaluación fue precipitada por la abrupta reducción -que tuvo comienzo a mediados de 1981de la tasa de entrada de capital al país. La crisis se vio acentuada aún más por el hecho que las leyes laborales vigentes a finales de 1981 y a principios de 1982, virtualmente, prohibían cualquier disminución en los salarios reales y, además, por la coincidencia de que en agosto de 1981 se efectuó un reajuste salarial de aproximadamente un 15\%; casi en el momento en que la situación macroeconómica chilena empezaba a requerir una reducción significativa de las remuneraciones reales”. HARBERGER (1984) p. 123.

57 El principio de legítima confianza consiste en la protección que tiene el ciudadano ante cuadros de confianza generados por sucesivos actos del Estado. Ver por ejemplo GARCÍA (2002) y GARCÍA DE ENTERRÍA (2002). 
sector privado..." y “aumentar obligatoriamente sus remuneraciones...": es que el aumento de remuneraciones solo es constitucionalmente admisible en el marco del ingreso mínimo, y jamás fuera de ese concepto, so pena de pugnar con otros derechos y valores constitucionales que se revisan más adelante.

Una segunda forma de interpretar esas dos frases en la Carta consiste en admitir que la ley podría aumentar los sueldos privados más allá del incremento del ingreso mínimo. Si así fuere, ¿cuál es su límite constitucional? La sección siguiente indagará sobre este problema.

4.4 DEL SENTIDO Y ALCANCE DE LA INICIATIVA LEGISLATIVA EXCLUSIVA DEL PRESIDENTE PARA “AUMENTAR OBLIGATORIAMENTE” LAS REMUNERACIONES DE LOS TRABAJADORES DEL SECTOR PRIVADO (ART. $65 \mathrm{~N}^{\circ} 4 \mathrm{CPR}$ )

Para hacerse cargo de la cuestión anterior es ineludible referirse en detalle a la iniciativa legislativa exclusiva del Presidente de la República. En efecto, aquí interesa determinar si es una atribución ilimitada, irrestricta amplia y discrecional, o está sometida a ciertos límites y condicionamentos constitucionales ${ }^{58}$.

Como sabemos, las materias de iniciativa exclusiva del Presidente de la República son aquellas que solo pueden transformarse en ley si el Presidente de la República resuelve enviar el Mensaje respectivo al Congreso, según lo establece el artículo 65 de la Constitución. El constituyente desea que todas las leyes que tengan un impacto económico en la vida nacional, sean iniciadas por quien tiene a su cargo "el gobierno y la administración del Estado”, esto es, el Presidente de la República.

Ahora bien, entre las materias de iniciativa exclusiva presidencial que se agrupan bajo el $\mathrm{N}^{\circ} 4$ del artículo 65 se ubica:

"40.- (...) fijar las remuneraciones minimas de los trabajadores del sector privado, aumentar obligatoriamente sus remuneraciones y demás beneficios económicos o alterar las bases que sirvan para determinarlos (...)”.

La pregunta relevante para este artículo es la siguiente: ¿hay en esta norma constitucional una autorización genérica al legislador para aumentar discrecionalmente las remuneraciones de los contratos vigentes de los trabajadores del sector privado?

Si bien podemos rastrear intentos en esta materia desde la promulgación de la Constitución de $1925^{59}$, no sería hasta la gran reforma constitucional de 1970, a través de la ley $\mathrm{N}^{\circ} 17.284$ donde se establecería claramente aquellas materias en las que el Presidente gozaría de iniciativa exclusiva ${ }^{60}$.

\footnotetext{
${ }^{58}$ En esta parte hemos utilizado algunas ideas que desarrollamos en FERMANDOIS y GARCíA (2009).

59 SILVA BASCUÑÁN (2000) p. 200.

${ }^{60}$ Los autores de la época respaldan la reforma constitucional de 1970, principalmente porque impide a los parlamentarios alterar la coherencia global del sistema económico-social. Hasta la fecha ello se producía por la vía de proyectos de ley parlamentarios y también de indicaciones parlamentarias, las que alteraban la coherencia global del sistema. Ver, por ejemplo, MOLINA (1970) p. 81.
} 
Ahora bien, las facultades legislativas del Presidente de la República en materia laboral del sector privado, provienen también desde $1970^{61}$, casi en el mismo texto vigente hoy en el artículo $65 \mathrm{~N}^{\circ} 4$ de la CPR.

Por ello, útil resulta revisar la forma en que los tratadistas de la época (los de la reforma constitucional de 1970) abordaron este tópico.

Silva Bascunán ya advertía en esa época que la iniciativa laboral exclusiva del Presidente no lo habilitaba para llegar a extremos incompatibles con una economía libre. Así, la facultad legal será solo para imponer remuneraciones mínimas al sector privado, pero jamás "máximas", ni tampoco para imponer escalas, pautas o montos directos de remuneración ${ }^{62}$.

Lo interesante es que emerge el límite natural a la facultad de aumentar remuneraciones del sector privado por ley. Considerando que este sector económico se encuentra por definición sustraído de "la ordenación directa del Estado", como dice el autor refiriéndose al sector público, entonces no resulta concebible una intervención legislativa que fije u ordene las remuneraciones privadas.

Es cierto que el límite señalado por este tratadista es bastante extremo: solo operaría si el Ejecutivo y Congreso desean aprobar escalas de remuneraciones para el sector privado, imponer montos o pautas para fijarlas. Pero también es efectivo que la reflexión de Silva Bascuñán prueba que hay un límite constitucional que no resulta lícito trasponer al ejercer esta facultad. El lo formula como un "principio básico de economía libre”. Tratándose de un constitucionalista, el autor está sin duda subrayando el sustrato constitucional que conforma un sistema económico basado en la libertad.

Un segundo aspecto relevante en esta materia y que fuera extensamente analizado por los tratadistas de la reforma constitucional de 1970, consiste en armonizar la facultad del Presidente de enviar proyectos de ley para aumentar remuneraciones privadas, con el ejercicio del derecho de los trabajadores a la negociación colectiva, establecido en el inciso quinto del artículo $19 \mathrm{~N}^{\circ} 16$ de la Carta Fundamental.

Sabemos que la negociación colectiva es un procedimiento contemplado por la Constitución que habilita a los trabajadores precisamente para discutir, solicitar, contraofertar y, en definitiva negociar con sus empleadores, los términos de sus contratos de trabajo. Sabemos también que las remuneraciones son un elemento esencial del contrato de trabajo, sin el cual este deriva en otro distinto. La inquietud aquí es entonces la siguiente: ¿cómo se armoniza la facultad legislativa de aumentar remuneraciones privadas con el derecho a la negociación colectiva? ¿Opera un mecanismo en subsidio de otro? ¿Es uno excluyente del otro?

${ }^{61}$ En lo pertinente: "Corresponderá exclusivamente al Presidente de la República la iniciativa... para fijar los sueldos o salarios minimos de los trabajadores del sector privado, aumentar obligatoriamente remuneraciones $y$ demás beneficios económicos o alterar las bases que sirven para determinarlos (...)".

62 Sostiene al autor: "No quedan, por lo tanto, en el campo reservado a la exclusividad del Presidente, las leyes que fijen los montos, escalas o pautas de remuneración, ni las que determinen remuneraciones máximas, formas de intervención legislativa que no parecen concebibles dentro del principio básico de un campo de economía libre, o sea, de una esfera productiva que quede al margen del control u ordenación directa del Estado". SILVA BASCUÑ́́N (1970) p. 103. 
El Ministro de Justicia a la época de la reforma constitucional de 1970, Gustavo Lagos Matus, al rebatir a los sindicatos los cargos sobre eventuales restricciones de la reforma al ejercicio de ciertos derechos laborales y sindicales ${ }^{63}$, sostuvo que el derecho de los trabajadores a la negociación colectiva queda inalterado y plenamente resguardado con motivo de la reforma constitucional de 1970; y que la facultad Presidencial y del Congreso de imponer sueldos mínimos y de aumentar las remuneraciones al sector privado, tenía (ya en 1970) un carácter supletorio al mecanismo de la negociación colectiva y era excepcional, al ejercerse solo "si a través de los mecanismos indicados" los sueldos privados "no alcanzan niveles satisfactorios" 64 .

Ahora bien, los comentarios de Lagos Matus se formulan en un marco constitucional radicalmente distinto del actual, dirigista intensamente en lo económico, en el que la Carta Fundamental de 1925 permitía sin reparos la fijación de los precios básicos de la economía: moneda extranjera, salarios y bienes básicos. Hoy hay consenso en que, salvo los bienes monopólicos o encontrándose decretado un estado de excepción constitucional, y exceptuando las facultades del Banco Central en el manejo de la política monetaria, la Constitución de 1980 no tolera la fijación de precios en la economía, ni siquiera por ley. Además, en cuanto a la protección del trabajo, la Carta de 1925 facultaba expresamente a la ley para "proporcionar a cada habitante un minimo de bienestar, adecuado a la satisfacción de sus necesidades personales y a las de su familia”. Agregaba "La ley regulará esta organización" (art. 10 N 14, Constitución de 1925).

Así, el contexto constitucional en que llega la iniciativa exclusiva para "aumentar remuneraciones" es completamente antagónico al de 2008, en que no existen remisiones a la ley para asegurar específicamente "el bienestar" ni una remuneración justa, como se verá más adelante.

Asimismo, del análisis de Lagos Matus se desprende la exigencia de un diagnóstico previo y específico del Presidente sobre insuficiencia en remuneraciones privadas. De este trabajo se desprende que aun en un marco de economía fuertemente estatizada, la facultad de fijar sueldos mínimos o aumentar las remuneraciones al sector privado requiere un diagnóstico previo y específico del Presidente de la República: que las remune-

\footnotetext{
${ }^{63}$ Lagos (1970) p. 61. No deja de ser interesante el hecho que en la CENC se enfrentara la misma interrogante desde la perspectiva sindical. Como sostuvo el comisionado Evans en sesión 200 del 7 de abril de 1976, p. 7: "Advierte que lo que sí falta, es una frase final que diga "sin perjuicio de los acuerdos a que lleguen las partes" -o algo así-, que salve la posibilidad de que la convención reemplace a la ley, si esta no se dicta, e incluso si llega a dictarse, para que prevalezca el acuerdo a que se ha llegado en una empresa, el cual puede ser más amplio, comprensivo, generoso, activo, que el que disponga el texto legal. Recuerda que esto recoge, también, una inquietud que planteó en la Comisión un dirigente sindical en el sentido de que aspiraba a que la Constitución establezca que la ley no podría dejar sin efecto las conquistas obtenidas por los trabajadores. Comprende que ello no es posible en algunas materias y en ciertas circunstancias extraordinarias, pero la participación que vayan logrando los trabajadores en la gestión, la dirección, las utilidades, los beneficios -ya en forma más genérica, por cierto-, si se han obtenido legítimamente, no pueden derogarse, a su juicio, por un legislador posterior".

${ }^{64}$ LAGOS (1970) pp. 64-65.
} 
raciones no han alcanzado un nivel satisfactorio producto de las negociaciones laborales y por esa razón debe recurrirse al mecanismo supletorio de la ley ${ }^{65}$.

Finalmente, Guillermo Piedrabuena escribiendo en aquella época, compatibiliza esta atribución con la negociación colectiva de los trabajadores, reforzando decididamente entonces, el carácter supletorio de la ley en los reajustes de salarios del sector privado, para el aumento de sus remuneraciones. La iniciativa del Presidente de la República operaría solo para los trabajadores que están privados de la posibilidad de negociar colectivamente ${ }^{66}$. En cuanto a los trabajadores que teniendo derecho a la negociación colectiva, en la práctica no lo hacen, Piedrabuena deduce que también podría aquí intervenir el legislador fijando los reajustes.

Más tarde, la Constitución de 1980 mantendrá y ampliará la órbita de materias que quedaron de iniciativa exclusiva del Presidente en la Constitución de 1925 luego de la reforma de 1970. Preparándose la actual Carta, el informe de la Comisión de Estudio para la Nueva Constitución (CENC), también llamada comisión Ortúzar, expresa que:

"El anteproyecto otorga, asimismo, especiales atribuciones al Presidente de la República para ejercer la administración económica del país [...] Al efecto como se verá al tratar de las atribuciones de carácter legislativo del Presidente de la República, amplía considerablemente la iniciativa exclusiva del Presidente de la República en todas aquellas materias administrativas, económicas, financieras, previsionales y otras que, en general, pueden importar gastos al erario" 67.

Ello en lo general: hay un reforzamiento de la iniciativa exclusiva. Sin embargo, en lo específico de materias laborales, se mantiene prácticamente sin modificaciones lo aprobado en la reforma constitucional de 1970.

Un análisis superficial de este fragmento del trabajo de la CENC podría llevar a concluir que el Presidente de la República, en la actualidad y bajo la Constitución de 1980 , tiene las mismas atribuciones para proponer aumentos de remuneraciones privadas que bajo la Carta de 1925. Sin embargo, ello implica desconocer el sentido libertario del orden público económico consagrado en la actual Carta Máxima.

\subsection{ANTECEDENTES ADiCiOnAlEs: FALlO DEL TC (1982) Y USO DE LA FACULTAD POR EL PRESIDENTE}

\subsubsection{Jurisprudencia del TC: Rol No 15 (1982)}

Los registros del Tribunal Constitucional exhiben un temprano caso en que se pronunció sobre una materia análoga en el pasado. Se trata de la sentencia Rol $\mathrm{N}^{\circ} 15$,

\footnotetext{
65 Debe registrarse que casi 40 años más tarde, en 2008, el Ministro del Trabajo y Previsión Social Osvaldo Andrade coincidiría exactamente con su colega de 1970, al advertir que el aumento de remuneraciones es materia de las negociaciones entre empleadores y trabajadores, y no de la ley. Historia de la Ley $N^{\circ} 20.281$, p. 32 .

${ }^{66}$ Piedrabuena (1970) pp. 110-111.

${ }^{67}$ SiLVA BASCUÑÁN (2000) p. 111.
} 
de 29 de noviembre de $1982^{68}$, en que analizó algunas disposiciones transitorias $\left(1^{\circ}, 2^{\circ}\right.$ y $4^{\circ}$ ) del proyecto de ley que más tarde se convertiría en la Ley $18.198^{69}$, modificatorio de los decretos Leyes 2.200 de 1978 y 2.758 de 1979 . El eje del fallo estará dado por el análisis de los artículos $1^{\circ}$ y $2^{\circ}$ transitorio de la ley $\mathrm{N}^{\circ} 18.198^{70} 71$.

Como sostiene críticamente Stillerman, lo que buscaba la autoridad de la época era enmendar nuevamente el Plan Laboral" y permitir "que todas las negociaciones colectivas pudiesen empezar de cero: los empleadores podían pagar salarios más bajos que el piso de 1979 fijado en la ley de junio de ese año"73.

El proyecto modificaba el artículo $6^{\circ}$ del D.L. 2200, en materia de negociación colectiva, y en opinión del Gobierno, en defensa de la modificación:

"tanto los aspectos de fondo como los de forma de la negociación colectiva, constituirán meras expectativas para las partes (...) Las estipulaciones de los contratos colectivos se habrían incorporado al patrimonio de los trabajadores solo en cuanto se refieren a servicios prestados o remuneraciones devengadas. Los servicios y remuneraciones por prestarse y devengarse constituyen meras expectativas, regulables por dis-

68 Requerimiento de constitucionalidad formulado por la Junta de Gobierno en virtud del artículo 82 No 2 de la Constitución, respecto del proyecto de ley que modifica los artículos $6^{\circ}$ del D.L. N ${ }^{\circ} 2.200$, de 1978; y 26, 28, 49 y 60 del D.L. No 2.758, de 1979.

69 Publicada en el Diario Oficial el día 31 de diciembre de 1982.

70 "Artículo $1^{\circ}$ transitorio. Al extinguirse un contrato colectivo celebrado con anterioridad a la vigencia de esta ley, las remuneraciones y beneficios pactados en dinero en las estipulaciones que deban subsistir como parte integrante de los contratos individuales de los respectivos trabajadores, en conformidad al inciso quinto del artículo $6^{\circ}$ del decreto ley $N^{\circ} 2.200$, se considerarán conforme al valor que tengan a la fecha de entrada en vigor del presente cuerpo legal.

Con todo, si el contrato colectivo a que se refiere el inciso anterior fuere modificado durante la vigencia de esta ley, no regirá lo dispuesto en el inciso precedente y será aplicable lo prescrito en el inciso quinto del artículo $6^{\circ}$ del decreto ley $\mathrm{N}^{\circ} 2.200$ ".

71 "Artículo $2^{\circ}$ transitorio. En la primera negociación que se efectúe en una empresa en que exista un contrato colectivo vigente a la fecha de entrada en vigor de esta ley, si la Comisión Negociadora ejerce el derecho que le confiere el inciso segundo del artículo 49 del decreto ley $\mathrm{N}^{\circ} 2.758$, las estipulaciones del nuevo contrato colectivo que se refieran a remuneraciones y beneficios pactados en dinero deberán suscribirse en conformidad a los valores que tengan a la fecha antes indicada.

Lo dispuesto en el inciso precedente será también aplicable si el trabajador ejerce el derecho que le confiere el inciso tercero del artículo 60 del decreto ley $\mathrm{N}^{\circ} 2.758$.

En los casos previstos en los incisos anteriores, deberán excluirse las estipulaciones relativas a la reajustabilidad de las remuneraciones y demás beneficios pactados en dinero.

Con todo, lo dispuesto en los dos primeros incisos no tendrá lugar cuando el contrato colectivo vigente a la fecha de entrada en vigor de esta ley hubiere sido modificado posteriormente, ni respecto de los trabajadores involucrados en la negociación cuyos servicios se hubieren iniciado a contar de la fecha antes indicada. En ambos casos regirán las normas permanentes establecidas en los artículos 49 y 60 del decreto ley $\mathrm{N}^{\circ} 2.758$.

Si en la empresa hubiere más de un contrato colectivo vigente a la fecha de entrada en vigencia de esta ley, las disposiciones de los incisos precedentes se aplicarán separadamente respecto de cada una de las negociaciones que se produzcan en aquella”.

72 Un conjunto de medidas diseñadas y aplicadas desde 1979 para flexibilizar el mercado laboral, de la mano del entonces Ministro del Trabajo, José Piñera. Ver PiÑera (1990).

73 STILLERMAN (2006) p. 186. 
posiciones que alteren las bases para determinarlas y las modalidades de la negociación colectiva"74.

El problema jurídico que enfrentaba el TC fue determinar si la llamada Ley del Piso de 1979 (DL 2.758) -que garantizaba al menos el IPC en las negociaciones colectivas-, confirió derechos adquiridos a los trabajadores. ¿Había o no vulneración al derecho de propiedad garantizado en la Carta Fundamental si una ley posterior eliminaba ese "piso" de reajustabilidad?

Sostuvo el Tribunal:

“4) (...) Sobre el particular expresó entonces esa Comisión ${ }^{75}$, cuyo criterio compartimos, textualmente lo siguiente: "Esta cuestión no merece dudas a vuestra Comisión, en el sentido de que el legislador es soberano para modificar, en la forma que estime conveniente y de acuerdo con los intereses generales del pais, los beneficios que hubiere otorgado a sus servidores o a los asalariados en general. Se trata de derechos conferidos por el legislador y que el mismo legislador puede, por lo tanto, ampliar, reducir y aun suprimir, sin otra limitación que la que dice relación con aquellos que se han incorporado realmente al patrimonio de los afectados con anterioridad a la ley. La ley que estatuye estos beneficios, como asimismo la que los modifica, tiene el carácter de administrativa y orden público, respectivamente, según sea el caso y, en consecuencia, rige in actum, porque en esta materias, como lo reconoce la doctrina y la jurisprudencia, no hay derechos adquiridos".

De este fallo destacamos, en primer lugar, que se trata de un fallo que sigue la línea clásica de la doctrina en materia laboral, en cuanto a que las leyes que rigen en este ámbito son de derecho público y no dan lugar a derechos adquiridos.

No obstante lo anterior, y en segundo lugar, es una sentencia que reconoce muchas diferencias en los hechos y el Derecho de ese año (1982), con el asunto que nos presenta la ley No 20.281, en 2008 .

El primer elemento diferenciador es el efecto jurídico de la ley sometida a control: mientras la ley No 18.198 eliminaba en sus artículos transitorios la reajustabilidad de los sueldos objeto de la negociación colectiva (derecho conferido por ley en 1979), la ley No 20.281 lo que hace es aumentar las remuneraciones. Mientras aquella reducía las expectativas de reajuste de remuneraciones para ajustarlas a la recesión económica del momento, la ley No 20.281 ordena el aumento concreto de los sueldos, con recursos de los empleadores privados. Creemos que esta es una diferencia crucial, que explica una natural tolerancia del TC a la ley de 1982, pero que podría exigir un criterio más estricto con la ley No 20.281, porque en esta última el legislador dispone concreta y materialmente de recursos económicos de privados, ordenándoles aumentar fuertemente las remuneraciones;

74 STC ROL No 15-1982 (Vistos).

75 Se refiere al Informe de la Comisión de Constitución, Legislación, Justicia y Reglamento del Senado, evacuado bajo la presidencia del eminente jurista don Fernando Alessandri, con fecha 5 de enero de 1956. 
Un segundo elemento diferenciador es la fuente del beneficio alterado por la ley sometida a control. Mientras en 1982 la fuente del beneficio (reajustabilidad o "piso" del IPC en las negociaciones colectivas) fue una ley previa de 1979, en el caso de la ley No 20.281 se impactan las remuneraciones vigentes en el contrato, cuya fuente es la voluntad de las partes. Es así como en 1982 el Tribunal aplicó el viejo aforismo de que "las cosas se deshacen como se hacen": si la ley confirió el beneficio, la ley lo puede privar. Esto no resulta aplicable al caso objeto de este Informe.

El tercer elemento es de contexto constitucional: ocurre que el informe del Senado citado por el TC en 1982, aquel fechado en 1956 bajo la presidencia de esa Corporación de don Arturo Alessandri, alude al texto del artículo $10 \mathrm{~N}^{\circ} 14$ de la Constitución de 1925, en cuanto deber del legislador de "proporcionar a cada habitante un minimo de bienestar, adecuado a la satisfacción de sus necesidades personales y a las de su familia..."; sabemos que la Constitución de 1980 eliminó esta frase y cambió radicalmente su enfoque, por aquel de una justa retribución, que será fijada preferentemente por la negociación colectiva y su solución "pacífica y justa”.

Por último, hay que subrayar que al tiempo de la sentencia rol $\mathrm{N}^{\circ} 15$, de 1982 , el Tribunal Constitucional caminaba sus primeros metros; tenía poco más de un año de funcionamiento, carecía de una identidad interpretativa propia, no había desarrollado un sistema pleno de principios interpretativos, y ni la literatura nacional de derecho público lo había hecho en un mínimo aceptable, etc. En doctrina constitucional, las sentencias de la década de 1980 tienen un valor menos intenso que las posteriores, precisamente por estas circunstancias.

Con todo, la sentencia rol $\mathrm{N}^{\circ} 15$ es un antecedente relevante a ponderar, porque va en la línea de facultar al legislador para intervenir en materia de remuneraciones.

\subsubsection{Registro de Mensajes y Leyes que aumentan remuneraciones}

Un último antecedente que nos parece relevante verificar dice relación con cuál ha sido la conducta constitucional del Presidente de la República en el pasado, cuando ha ejercido su facultad de enviar Mensajes al Congreso para aumentar las remuneraciones del sector privado, o proyectos que impactan esas remuneraciones.

El Presidente lo ha hecho en muy escasas oportunidades durante los últimos 20 años, lo que pone de manifiesto el carácter excepcionalísimo de este instrumento.

En primer lugar, encontramos la ley No 19.464 que "establece normas y concede un aumento de remuneraciones para el personal no docente de establecimientos educacionales que indica"76, donde se otorgó a los colegios subvencionados una subvención especial con el único objeto de que ella se transforme en el pago de una mayor remuneración al personal no docente de los establecimientos educacionales.

En segundo lugar, y modificando la anterior, se encuentra la ley No 20.244 que "introduce modificaciones a la ley $N^{\circ} 19.464$ y otorga otros beneficios que indica"77, que

\footnotetext{
${ }^{76}$ Publicada en el Diario Oficial el 16 de julio de 1996. Proyecto de Ley Boletín 1741-04, ingresado el 9 de noviembre de 1995 .

77 Publicada en el Diario Oficial el 19 de enero de 2008. Proyecto de Ley Boletín 5085-04, ingresado el 30 de mayo de 2007.
} 
otorga a los asistentes de educación (paradocentes o codocentes) un bono por desempeño de excelencia.

Finalmente, encontramos la ley No 19.988 que "modifica el Código del Trabajo, en materia de remuneraciones por jornada extraordinaria y de trabajadores temporeros agrícolas"78, que establece que el cálculo del valor de las horas extraordinarias, no podrá efectuarse sobre una base inferior al ingreso mínimo mensual, tanto para los trabajadores con jornada completa como parcial. Asimismo, se obliga a las empresas que contraten trabajadores de temporada (en la agricultura), a depositar los saldos de remuneraciones que resultaren a favor del trabajador, en la cuenta individual para seguro de desempleo.

Estas tres leyes presentan las siguientes características. Primero, dos de las tres leyes citadas se refieren a personal de escuelas municipalizadas y particulares subvencionadas, esto es, a un sector en que el Estado se encuentra involucrado protagónicamente con sus propios recursos, lo que en absoluto ocurre con la ley $\mathrm{N}^{\circ} 20.281$ que afecta al sector privado puro y simple. La ley restante ( $\mathrm{N}^{\circ}$ 19.988) se refiere a trabajadores temporeros de la agricultura, y se refleja en un cambio en la forma de calcular las horas extraordinarias con una disposición lógica, como fue obligar a que la base de cálculo de estas horas sea el ingreso mínimo mensual.

Segundo, las leyes incluyen en su Mensaje una indicación clara de su efecto económico, a diferencia de lo sucedido con el Mensaje de la ley 20.281. Un ejemplo es la ley 19.464, cuyo mensaje es nítido y preciso: "Establece normas y concede un aumento de remuneraciones para el personal no docente de establecimientos educacionales que indica".

Tercero, las dos leyes cuyos mensajes no explicitaron un aumento de remuneraciones, concedieron bonos anuales determinados, no permanentes, o alteraron la mecánica de cálculo de horas extraordinarias en armonía con el sueldo mínimo. Como se ve, ninguna realmente significó en rigor un aumento de remuneraciones.

\subsection{ARMONizaCión del ARTíCulo 65 No 4 CON 19 No 16 DE LA CPR}

Es indudable que nuestro ordenamiento consagra un margen razonable al legislador para definir los parámetros bajo los cuales un contrato de trabajo debe ser celebrado, en virtud del principio general de la regulación y complementación por ley de los derechos constitucionales según se establece en el artículo 19 numeral 26 de la Constitución.

Sin embargo, una interpretación sistemática y finalista del alcance y sentido el artículo $65 \mathrm{~N}^{\circ} 4$ de la Constitución y todas las normas referidas, nos lleva a concluir que no sería constitucionalmente admisible que el legislador determine íntegramente el contenido de los elementos esenciales del contrato de trabajo, ni, como dice Silva Bascuñán, "imponga montos, escalas o pautas de remuneraciones"79.

En este sentido, la actual Constitución reproduce en esta materia exactamente las frases provenientes de la Carta de 1925. Con todo, el contexto en que esta atribución presidencial se introdujo a esta última fue radicalmente diferente al vigente durante el

78 Publicada en el Diario Oficial el 18 de diciembre de 2004. Proyecto de Ley Boletín 3696-13, ingresado el 4 de octubre de 2004.

79 Silva BASCUÑ́N (1970) p. 81. 
Texto Fundamental de 1980; en efecto, la Carta de 1925, en cuanto a la protección del trabajo, facultaba expresamente a la ley para "proporcionar a cada habitante un minimo de bienestar, adecuado a la satisfacción de sus necesidades personales y a las de su familia", agregando que "La ley regulará esta organización" 80.

Así, la Constitución de 1980 al establecer el "derecho a la libertad de trabajo y su protección” otorga un enfoque distinto al tratamiento que en la materia tuvo a la Carta de 1925, creándose como nuevo derecho la "libre contratación y la libre elección del trabajo con una justa retribución”.

Estos cambios y evoluciones en el texto tuvieron por objeto configurar a la justa retribución como un derecho social, lato sensu, y no un derecho stricto sensu. En efecto, y como vimos anteriormente ${ }^{81}$, los constituyentes pensaban que esta clase de derechos no era garantizable simplemente con leyes, mediante decisiones que produzcan un disfrute instantáneo del derecho, sino que este sería progresivo, de acuerdo a la capacidad económica del país.

En otras palabras, el elemento sistemático de interpretación constitucional -tantas veces invocado por el Tribunal Constitucional_82 aconseja evitar la interpretación aislada del artículo $65 \mathrm{~N}^{\circ} 4$, e impide arribar hoy a la misma conclusión que la hubiere correspondido si se encontrare vigente el Código Supremo de 1925. En efecto, ello obliga a construir una interpretación razonable, que permita conciliar el artículo $65 \mathrm{~N}^{\circ} 4$ del Código Básico con principios, derechos, garantías inexistentes en la Carta de 1925, pero vigentes en el día de hoy, y en especial, con la denominada Constitución Económica y con los principios contenidos en el Capítulo I de la Carta Máxima sobre bases de la institucionalidad.

\footnotetext{
${ }^{80}$ Artículo $10 \mathrm{~N}^{\circ} 14$ CPR (1925).

81 IRURETA (1992) pp. 491-92.

82 En esta línea se ha pronunciado el Tribunal Constitucional en el reciente fallo STC 815, del 19 de agosto de 2008, considerando $4^{\circ}$ señala "En consecuencia, interpretada armónicamente la Constitución después de la modificación del artículo 19 número $3^{\circ}$ por la Ley No 19.519, debe necesariamente concluirse que la investigación está concebida como una vía para llegar a un proceso jurisdiccional...”. En el mismo fallo, los Ministros Bertelsen, Correa y Fernández en una prevención en fallo reciente e invocando los precedentes en esta materia: “(...) recogido en múltiples oportunidades por reiterada doctrina de esta misma Magistratura acerca de que la inteligencia que se dé a un precepto de la Carta Fundamental debe resultar armónico con las restantes normas del mismo cuerpo, de modo de asegurar la efectiva vigencia de todos sus precepto". STC 815, 19 de agosto de 2008, considerando $4^{\circ}$. En la misma línea, véase el considerando 17 del STC 309 de 4 de agosto de 2000, que señala "Que una interpretación armónica y sistemática de los artículos 50, $N^{\circ}$ 1) y 63, inciso segundo, del Código Fundamental llevan, indubitadamente, a la conclusión que si un tratado internacional contiene normas propias de ley orgánica constitucional, el acuerdo del Congreso para su aprobación o rechazo exige el quórum establecido por la Constitución para esa clase de leyes". Véase también el considerando 23 del STC 325 de 26 de junio de 2000, que señala: "Que, si reflexionamos con profundidad sobre las modificaciones introducidas por el Poder Constituyente a estas normas, las relacionamos dándole su pristino significado en una interpretación de contexto y armónica y traemos a colación los principios de hermenéutica constitucional...". Véase también el considerando tercero del STC 596 de 12 del julio de 2007, que señala: "Que para dar aplicación jurisdiccional a esta disposición debe, en primer término, precisarse el alcance, para este solo efecto, de la expresión "acusado" que emplea la Carta Fundamental, con el fin de lograr una interpretación armónica entre el texto constitucional, que se limitó a sustituir la voz "procesado" por "acusado" para estos efectos, y el precepto legal que regula el procedimiento establecido para el desafuero por delitos de acción privada, contenido en el nuevo Código Procesal Penal”. Estas ideas han sido también expresadas en los fallos del Tribunal Constitucional Roles 383, 392 y 396.
} 
Ello es además coherente con las tendencias modernas en materia de negociación colectiva $^{83} 84$.

\section{CONCLUSIONES}

Este trabajo analizó el caso de la ley No 20.281, de 2008 sobre "salarios base" y conocida como de "beneficio de la semana corrida", como ejemplo de confluencia de la intervención legislativa en las remuneraciones del sector privado, por una parte, y la libertad de contratación como derecho constitucional, por otra.

Hemos concluido aquí que la facultad conferida al Presidente de la República en el artículo $65 \mathrm{~N}^{\circ} 4$ de la Carta Fundamental, que entre otras materias de iniciativa exclusiva contiene la de "fijar las remuneraciones mínimas de los trabajadores del sector privado, aumentar obligatoriamente sus remuneraciones y demás beneficios económicos(...)”, no fue correctamente ejercida en la ley No 20.281, en términos de resultar armónica y respetuosa de la Carta Fundamental con el derecho a la "libre contratación y a la libre elección del trabajo con una justa retribución", según se establece en el artículo 19 numeral 16 de la Carta Fundamental.

La atribución legislativa presidencial para intervenir salarios del sector privado, vigente en idénticos términos desde 1970 en la Carta Fundamental, fue utilizada en este caso siguiendo la lógica con que fue diseñada hace varias décadas, bajo un marco constitucional radicalmente distinto al actual.

Aun bajo aquel contexto, la literatura de la época (1970) formuló prevenciones sobre el alcance de la nueva materia de iniciativa exclusiva presidencial que entraba a la Carta de 1925. Los autores acotaron sus efectos a un plano supletorio de la voluntad de las partes y de la negociación colectiva. Las remuneraciones no podrían elevarse, para el sector privado, directamente por ley. En este sentido escribieron Lagos Matus, Piedrabuena Richards y Silva Bascuñán, este último advirtiendo que no sería admisible que el legislador "imponga escalas o pautas de remuneraciones" 85.

${ }^{83}$ En efecto, estas proponen un nuevo marco regulatorio, donde los principales lineamientos apuntan a: 1. Liberalización de la negociación en función del fomento de la autonomía colectiva, que se traduce en la supresión de prohibiciones y a la disminución del reglamentarismo. 2. En cuanto a los sujetos titulares de la negociación colectiva, se propone que las organizaciones titulares que mejor representen los intereses comprometidos en la negociación, se prioricen a aquellas que no, debiendo recaer en las organizaciones sindicales. 3. Asimismo, en cuanto a los niveles de negociación se propone una estructura negocial más flexible, con resguardos de la heterogeneidad productiva y responsabilidad en la resolución de controversias. 4. Respecto al ámbito de aplicación y efectos jurídicos de los instrumentos colectivos, se señala que el proceso de negociación debiese ser vinculante (obligar a negociar y a concordar). 5. Sobre las materias susceptibles de negociación colectiva y diálogo bipartito, las partes debiesen estar facultadas legalmente para negociar, dialogar y acordar sobre todas aquellas materias que afecten sus relaciones mutuas, incluidos los temas salariales y de condiciones de trabajo. 6. Restricción de la disposición unilateral del empleador (también conocida como negociación “in peius”), respecto a los derechos laborales mínimos. 7. Reconocimiento efectivo del derecho a huelga y la libertad sindical. Ver FERES e INFANTE (2007) p. 34 y ss.

${ }^{84} \mathrm{La}$ actual reforma, desde el punto de vista de la negociación colectiva significa un retroceso, toda vez que no apunta a la liberalización de ella, sino más bien restringe las materias que podrían regularse a través de ella.

85 SiLVA BASCUÑÁN (1970) p. 81. 
Si aquella fue la interpretación bajo la carta de 1925 sobre cómo conciliar el actual artículo 65 No 4 con la libertad de contratación, hoy aparece más nítidamente reprochable un aumento de salarios, más allá del ingreso mínimo, ordenado forzosamente por la ley al sector privado.

En efecto, el elemento sistemático de interpretación constitucional aconseja evitar la hermenéutica aislada del artículo $65 \mathrm{~N}^{\circ} 4$, e impide arribar hoy a la misma conclusión que le hubiere correspondido si se encontrare vigente el Código Supremo de 1925. En efecto, ello obliga a construir una interpretación razonable, que permita conciliar el artículo $65 \mathrm{~N}^{\circ} 4$ del Código Básico con principios, derechos, garantías inexistentes en la Carta de 1925, pero vigentes en el día de hoy, y en especial, con la denominada Constitución Económica y con los principios contenidos en el Capítulo I de la Carta Máxima sobre Bases de la institucionalidad.

En efecto, la ley No 20.281 ingresó al núcleo fundamental de la garantía de la libertad de trabajo, desbordando su ámbito propio y alterando un elemento esencial del contrato de trabajo, privativo de la negociación entre empleadores y trabajadores: las remuneraciones. La Constitución ha previsto que los salarios se fijen por la voluntad de las partes, expresada individualmente o luego de una negociación colectiva, y no por ley. La única excepción a esta regla la constituye el ingreso mínimo, compatible con los mínimos sociales que el legislador podría razonablemente abordar en nombre de la “justa retribución” a que alude el numeral 16 del artículo 19 del Código Básico.

$\mathrm{Y}$ es que de los antecedentes históricos y legislativos que hemos analizado, se desprende que el reajuste del sueldo o ingreso mínimo está conectado desde sus orígenes directamente con la inflación y su impacto en las remuneraciones. Por consiguiente, puede concluirse que los trabajadores y empleadores del sector privado pueden prever y hasta esperar un reajuste relativamente periódico del ingreso mínimo, conforme ha ocurrido en el pasado y en conexión con parte del alza del costo de la vida. Sin embargo, no resulta constitucionalmente previsible que las leyes ordenen aumentos que vayan más allá de dicho parámetro, como tampoco que ordenen alzas a sueldos que excedan ese mínimo. Ello repugnaría al principio constitucional de la legítima confianza, certeza jurídica y a la esencia del derecho a la libre contratación.

El diseño de la Carta Fundamental así lo ha ratificado, sintonizando la libertad de contratación en un marco más amplio de Constitución Económica u Orden Público Económico, que no solo apunta a las regulaciones del legislador, sino también a salvaguardar un margen razonable de libertad para los individuos que contratan. El ubicarse el contrato de trabajo en una zona de legislación proteccionista de los derechos del trabajador no elimina del todo la libertad de contratación; si así fuere, el inciso segundo del numeral 19 del artículo 19 de nuestro Código Máximo quedaría vaciado de todo contenido.

Ante las conclusiones anteriores, la ley No 20.281 es un caso de desborde legislativo no tolerado para la Constitución. Iniciada para equiparar el sueldo base al ingreso mínimo -sin aumento de salarios- se transformó en una imposición legal de aumento de remuneraciones para el sector privado, más allá del mínimo. Ello ocurrió como consecuencia de extender el beneficio de la semana corrida a trabajadores contratados por 
mes, y ya no solo por día, y aun cuando el sueldo base fuese superior al mínimo. Con esto, esta ley no satisfizo las exigencias de fondo previstas por la Carta Fundamental para tolerar un aumento obligatorio, sobreviniente y significativo de las remuneraciones pactadas en sus contratos por los trabajadores y empleadores del sector privado, en especial en cuanto al respeto del núcleo esencial del derecho a la libre contratación.

\section{BIBLIOGRAFÍA CITADA}

Cea Egaña, José Luis (2004): Derecho Constitucional Chileno (Santiago, Ediciones Pontificia Universidad Católica de Chile) Tomo II.

CRuz-COKe Ossa, Carlos (2005): Manual de Educación Cívica (Santiago, Ediciones Universidad del Desarrollo), 292 pp.

Evans De la CuAdra, Enrique (1999): Los Derechos Constitucionales (Santiago, Editorial Jurídica de Chile) Tomo III.

Feres, María Ester e Infante, Ricardo (2007): "La Negociación Colectiva del Futuro en Chile", en Colección Ideas, Año 8: pp. 1-46.

FERMANDOIS VÖHRINGER, Arturo (2006): Derecho Constitucional Económico (Santiago, Ediciones Universidad Católica de Chile) tomo I.

FERMANDOIS VÖHringer, Arturo y José Francisco García García (2009): "Origen del presidencialismo chileno: Reforma constitucional de 1970, ideas matrices e iniciativa legislativa exclusiva", Revista Chilena de Derecho, vol. 36 No 2: pp. 281-311.

Ferrada Bórquez, Juan Carlos (2000): "La Constitución económica de 1980. Algunas reflexiones críticas", Revista de Derecho, vol. 11: pp. 47-54.

FErrada BórqueZ, Juan Carlos (2003): "Los órganos reguladores de actividades económicas relevantes en Chile", Revista Chilena de Derecho, vol. 30 No 2: pp. 271-286.

Gaete Berríos, Alfredo (1967): Tratado de Derecho del Trabajo y Seguridad Social (Santiago, Editorial Jurídica de Chile) tomo I.

GARCÍA DE ENTERRÍA, Eduardo (2002): “El principio de protección de la confianza legítima como supuesto título justificativo de la responsabilidad patrimonial del Estado legislador", Revista de Administración Pública, No 159: pp. 173-208.

GarCÍA García, José Francisco (2009): “¿Inflación de Superintendencias? Una mirada crítica desde el derecho regulatorio", Actualidad Jurídica, vol. 19 No 1: pp. 327-372.

GARCÍA LuengO, Javier (2002): El principio de protección de la confianza en el derecho administrativo (Madrid, Editorial Civitas) 427 pp.

Guerrero del Río, Roberto (1979): "La Constitución Económica”, Revista Chilena de Derecho, vol. 6 No 1-4: pp. 79-94.

Harberger, Arnold C. (1984): "La Crisis Cambiaria Chilena en 1982", Cuadernos de Economía UC, N 63: pp. 123-136.

Humeres Noguer, Héctor (2007): Derecho del Trabajo y de la Seguridad Social (Santiago, Editorial Jurídica de Chile) tomo I.

Irureta Uriarte, Pedro (1992): “Consecuencias para la Libertad de Trabajo de un fallo de la Corte de Apelaciones de Santiago", Revista Chilena de Derecho, vol. 19 N $^{\circ}$ 3: pp. 489-508. 
Irureta Uriarte, Pedro (1993): "Libertad de Trabajo en la Constitución Política de 1980", en TAPIA, Francisco y Romagnoli, Humberto: Derecho del Trabajo: Normas y Realidad. Estudios en homenaje al Profesor Ramón Luco Larenas (Santiago, Ediciones Universidad Nacional Andrés Bello) pp. 35-55.

Kocher, Eva (2007): "El Impacto de la Globalización sobre la Estructura de las Relaciones Laborales en Alemania”, en AFDUDC, No 11: pp. 385-395. Ponencia leída y defendida en las "Jornadas Internacionales sobre el Impacto de la Globalización en las Relaciones Laborales", celebradas en la Facultad de Derecho de la Universidad de La Coruña los días 28 y 29 de mayo de 2007. Traducción del alemán de Jesús Martínez Girón.

Larroulet Vignau Cristián y Francisco Mochón Morcillo (1995): Economía (McGraw-Hill Interamericana) $661 \mathrm{pp}$.

Lagos Matus, Gustavo (1970): “Tres Temas centrales de la Reforma Constitucional”, en Frei Montalva, Eduardo, Sergio Molina Silva, Enrique Evans de la CuaDra, Gustavo Lagos Matus, Alejandro Silva Bascuñán y Francisco Cumplido CERECEDA: "La Reforma Constitucional de 1970" (Santiago, Editorial Jurídica de Chile) pp. 55-73.

Libertad Y Desarrollo (2008): "Semana Corrida, Mayores Costos para el País", Temas Públicos, № 882 .

MARINAKIS, Andrés (2006): "La Rigidez de los Salarios en Chile", Revista de la CEPAL, No 90: pp. 135-150.

Molina SILVA, Sergio (1970): "La planificación y la iniciativa exclusiva del Ejecutivo en materia económica y social', en FreI MONTALVA, Eduardo, Sergio MOlina Silva, Enrique Evans de la CuAdra, Gustavo Lagos Matus, Alejandro Silva BascuÑÁN y Francisco CUMPLIDO CERECEDA: "La Reforma Constitucional de 1970” (Santiago, Editorial Jurídica de Chile) pp. 74-90.

Piedrabuena Richards, Guillermo (1970): La Reforma Constitucional. Historia de la Ley 17.284, sus principales alcances y posición de los partidos politicos (Santiago, Ediciones Encina Ltda.) pp. 180-237 (Anexo No 6).

Piñera ECHEÑiQUe, José (1990): La Revolución Laboral en Chile (Santiago, Zig-Zag, $3^{a}$ ed.) $164 \mathrm{pp}$.

Ribera Neumann, Teodoro (2007): “La Protección Constitucional de la Empresa: la individualidad determinada y la teoría del levantamiento del velo", Sentencias Destacadas 2006 (Santiago, Ediciones Libertad y Desarrollo) pp. 275-298

Romero GuZmán, Juan José (2008): “¿Capturados por nuestra suspicacia? Algunas aproximaciones acerca del origen, desarrollo y extinción de las regulaciones”, Revista Chilena de Derecho, vol. 35 No 1, pp. 9-35.

SILVA BASCUÑán, Alejandro (1970): "El nuevo régimen de iniciativa exclusiva del Ejecutivo", en Frei Montalva, Eduardo, Sergio Molina Silva, Enrique Evans de la Cuadra, Gustavo Lagos Matus, Alejandro Silva Bascuñán y Francisco CumplDo CerecedA: "La Reforma Constitucional de 1970" (Editorial Jurídica de Chile) $300 \mathrm{pp}$. 
Silva Bascuñán, Alejandro (2000): Tratado de Derecho Constitucional (Santiago, Editorial Jurídica de Chile, 2a ed.) tomo VII.

STILlERMAN, Joel (2006): "Continuidades, rupturas y coyunturas en la transformación de los obreros de Madeco S.A., 1973-2003”, Política (INAP, Universidad de Chile) vol. 44: pp. 165-196.

Thayer Arteaga, William y Novoa Fuenzalida, Patricio (1998): Manual de Derecho del Trabajo (Santiago, Editorial Jurídica de Chile) 267 pp.

THAYER ARTEAGA, William (1985): “Tendencias actuales en el derecho del trabajo chileno", Revista Chilena de Derecho, vol. 14 No 3: pp. 447-454.

THAYER ARTEAGA, William (1994): “Orígenes, evolución y perspectivas del derecho laboral chileno”, Estudios Públicos, No 54: pp. 223-241.

VAldés PRIETO, Domingo (2006): Libre Competencia y Monopolio (Santiago, Editorial Jurídica de Chile) $751 \mathrm{pp}$.

Verdugo Marinkovic, Mario y Pfeffer Urquiaga, Emilio (2005): Derecho Constitucional (Santiago, Editorial Jurídica de Chile) tomo I.

yRarráZaVal Covarrubias, Arturo (1987): "Principios económicos de la Constitución de 1980", Revista Chilena de Derecho, vol. 14: pp. 97-112.

Zapata larraín, Patricio (2002): La Jurisprudencia del Tribunal Constitucional (Santiago, Universidad Andrés Bello) 200 pp.

\section{NORMAS CITADAS}

Ley No 20.281, modifica el código del trabajo en materia de salario base. Diario Oficial, 21 de julio de 2008.

Ley No 19.464, establece normas y concede un aumento de remuneraciones para el personal no docente de establecimientos educacionales que indica. Diario Oficial, 16 de julio de 1996.

Ley No 20.244, introduce modificaciones a la ley No 19.464 y otorga otros beneficios que indica. Diario Oficial, 19 de enero de 2008.

Ley No 19.988, modifica el Código del Trabajo en materia de remuneraciones para jornada extraordinaria y de trabajadores temporeros agrícolas. Diario Oficial, 18 de diciembre de 2004.

\section{JURISPRUDENCIA CITADA}

Requerimiento de constitucionalidad formulado por la Junta de Gobierno respecto del proyecto de ley que modifica los artículos $6^{\circ}$ del D.L. $N^{\circ} 2.200$, de 1978; y 26, 28, 49 y 60 del D.L. $N^{\circ}$ 2.758, de 1979 (1982): Tribunal Constitucional, Rol 15-1982 de 29 de noviembre de 1982. Disponible en: <http://www.tribunalconstitucional.cl/ index.php/sentencias/view/594> [fecha de consulta: 23 de septiembre de 2009]

Requerimiento de inaplicabilidad presentado por Patricio Rodrigo Meneses Farías respecto del artículo 230, inciso primero, del Código Procesal Penal, en la causa RIT $N^{\circ} 179$ 2005, RUC N 0510001570-08, del Juzgado de Garantía de San Fernando: Tribunal 
Constitucional, Rol 815-2008 de 19 de agosto de 2008. Disponible en: http:// www.tribunalconstitucional.cl/index.php/sentencias/view/996 [fecha de consulta: 23 de septiembre de 2009]

\section{OTRAS FUENTES}

Actas oficiales de la comisión de estudio de la nueva constitución. Disponible en: < http:// www.bcn.cl/histley/actas_oficiales> [fecha de consulta: 23 de septiembre de 2009] Historia de la ley 20.281, Modifica el código del trabajo en materia de salarios base. Disponible en: <http://www.bcn.cl/histley/lfs/hdl-20281/HL20281.pdf> [fecha de consulta: 23 de septiembre de 2009] 92 pp. 